\title{
Pancreatic cancer cachexia: a review of mechanisms and therapeutics
}

\section{Carlyn R. Tan ${ }^{1}$, Patrick M. Yaffee ${ }^{1}$, Laith H. Jamil' ${ }^{2}$, Simon K. Lo ${ }^{3}$, Nicholas Nissen ${ }^{1}$, Stephen J. Pandol ${ }^{3}$, Richard Tuli ${ }^{1}$ and Andrew E. Hendifar ${ }^{1,2 *}$}

1 Samuel Oschin Comprehensive Cancer Center, Cedars Sinai Medical Center, Los Angeles, CA, USA

2 Department of Medicine, David Geffen School of Medicine, Los Angeles, CA, USA

${ }^{3}$ Department of Medicine, Cedars Sinai Medical Center, Los Angeles, CA, USA

Edited by:

Mouad Edderkaoui, University of California Los Angeles, USA

\section{Reviewed by:}

Giamila Fantuzzi, University of

Illinois at Chicago, USA

Matthias J. Bahr, Sana Kliniken

Lübeck, Germany

*Correspondence:

Andrew E. Hendifar, Samuel Oschin

Comprehensive Cancer Center,

Cedars Sinai Medical Center, 8700

Beverly BIvd., suite 1042AC, Los

Angeles, CA 90402, USA

e-mail: andrew.hendifar@cshs.org
Over the last decade, we have gained new insight into the pathophysiology of cachexia associated with pancreatic cancer. Unfortunately, its treatment is complex and remains a challenge. Pancreatic cancer cachexia is a multifactorial syndrome characterized by uncompensated adipose tissue and skeletal muscle loss in the setting of anorexia that leads to progressive functional impairment. This paper will review the current concepts of pancreatic cancer cachexia, its assessment and pathophysiology as well as current and future treatments. The successful management of pancreatic cancer cachexia will likely require a multimodal approach that includes nutritional support and combination pharmaceutical interventions.

\section{Keywords: pancreatic cancer, cachexia, anorexia, catabolism, multimodal therapy}

\section{INTRODUCTION}

Cachexia is a ubiquitous characteristic of pancreatic cancer and develops in approximately $80 \%$ of pancreatic cancer patients during their disease course (Fearon et al., 2006b). Up to onethird die from complications associated with cachexia through immobility, severe respiratory muscle impairment resulting in cardiopulmonary failure, and impaired immunity (Bachmann et al., 2009). Cachexia is a complex metabolic disorder that involves features of anorexia, anemia, and loss of adipose and skeletal muscle mass. In pancreatic cancer patients, it has been associated with reduced physical function, lower response rates to chemotherapy and radiation treatment, and decreased survival (Dewys et al., 1980; Moses et al., 2004; Bachmann et al., 2008, 2009). Pre-operative evidence of cachexia in pancreatic cancer patients has been also associated with worse postoperative outcome after pancreaticoduodenectomy (Pausch et al., 2012).

Although new insights to the pathogenesis of pancreatic cancer cachexia have been gained over the past decade, the underlying mechanisms leading to this syndrome are not fully understood. There continues to be an active search for potential targets and effective treatment. This article reviews the current concepts and management of this clinical dilemma.

\section{DEFINITION AND CLASSIFICATION OF CANCER CACHEXIA}

Cachexia has been recognized as a common complication of cancer. In 2011, an international consensus defined cancer cachexia as a multifactorial syndrome characterized by ongoing loss of skeletal muscle mass that cannot be fully reversed by conventional nutritional support and leads to progressive functional impairment (Fearon et al., 2011). Diagnostic criteria include weight loss greater than $5 \%$ over the past 6 months, weight loss greater than $2 \%$ in individuals with body mass index (BMI) less than $20 \mathrm{~kg} / \mathrm{m}^{2}$, or evidence of sarcopenia with any degree of weight loss greater than 2\% (Table 1). Evidence of sarcopenia is defined as appendicular skeletal muscle index less than $7.26 \mathrm{~kg} / \mathrm{m}^{2}$ in males and less than $5.45 \mathrm{~kg} / \mathrm{m}^{2}$ in females determined by dual energy X-ray absorptiometry (DEXA). Based on these criteria, the majority of pancreatic cancer patients have cachexia at the time of diagnosis (Fearon et al., 2006b).

Cancer cachexia develops progressively through a spectrum. The international consensus identified three stages of cachexia: precachexia, cachexia, and refractory cachexia (Fearon et al., 2011). Severity is classified based on the degree of depletion of energy stores and body protein mass (using BMI) and the rate of ongoing weight loss. In precachexia, patients demonstrate early clinical and metabolic signs including anorexia and impaired glucose tolerance preceding substantial involuntary weight loss. Patients then develop progressive weight loss and meet the criteria for cachexia as previously defined. Cachexia becomes clinically refractory as a result of progressive cancer unresponsive to therapy. In this stage, there is active catabolism, and patients have worsening physical function with a life expectancy of less than 3 months.

\section{ASSESSMENT OF CANCER CACHEXIA}

Since cachexia is a multifactorial syndrome, its evaluation should involve assessment for various features as summarized in Table 2: anorexia or reduced food intake, catabolic drivers, muscle mass and strength, and functional and psychosocial effects (Fearon et al., 2011). Some of these different characteristics of cancer cachexia have been found to be adverse prognostic indicators. A recent study showed that weight loss ( $>10 \%$ weight loss), reduced food intake $(<1500 \mathrm{kcal} /$ day $)$, and evidence of systemic inflammation [C-reactive protein $(\mathrm{CRP})>10 \mathrm{mg} / \mathrm{L}$ ] identified 
Table 1 | Diagnosis of cancer cachexia (Fearon et al., 2011).

Weight loss greater than $5 \%$ over the past 6 months; or

Weight loss greater than $2 \%$ in individuals with BMI less than $20 \mathrm{~kg} / \mathrm{m}^{2}$; or Evidence of sarcopenia* with weight loss greater than $2 \%$

${ }^{*}$ Sarcopenia defined as appendicular skeletal muscle index in males $<7.26 \mathrm{~kg} / \mathrm{m}^{2}$ and in females $<5.45 \mathrm{~kg} / \mathrm{m}^{2}$ determined by DEXA.

Table 2 | Assessment of cancer cachexia.

\begin{tabular}{ll}
\hline Areas of assessment & Methods \\
\hline Reduced food & Patients estimate overall food intake \\
intake/ anorexia & $\begin{array}{l}\text { Third-party assessment of food intake } \\
\text { (family member) } \\
\end{array}$ \\
& Assess for mechanical factors contributing \\
& to reduced intake
\end{tabular}

\begin{tabular}{ll}
\hline Hypercatabolism & Serum CRP levels \\
& Responsiveness to treatment and rate of \\
& disease progression
\end{tabular}

Muscle mass and

strength

Cross-sectional imaging with $\mathrm{CT}$ or MRI

DEXA: appendicular skeletal muscle index

Anthropometry: mid-upper-arm muscle

area

Bioimpedance analysis: whole body fat-free mass index

Physical and

EORTC QLQ-C3O

psychosocial

ECOG questionnaire

functioning

Karnofsky performance score

Electric activity meters

Checklists of specific activities

CRP, C-reactive protein; CT, computed tomography; MRI, magnetic resonance imaging; DEXA, dual-energy X-ray absorptiometry; EORTC QLQ-C30, European Organization for Research and Treatment of Cancer quality of life questionnaire C-30; ECOG, Eastern Cooperative Oncology Group.

pancreatic cancer patients with reduced subjective and objective functional ability. Patients with at least two of these components had a significantly worse prognosis (Fearon et al., 2006b).

Evaluation of food intake should be routinely performed. At the minimum, patients can be asked to estimate their overall food intake in relation to normal intake with dietary or recall records. Another simple method for prospective third-party assessment of food intake is the percentile calculation of food consumed at each meal by a family member (Bruera and Sweeney, 2000). Patients should also be evaluated for underlying factors that contribute to reduced food intake, such as lack of appetite, chemosensory disturbances, dysphagia, decreased gastrointestinal (GI) motility, pain, and fatigue.

A key component of pancreatic cancer cachexia is hypercatabolism due to direct tumor metabolism, systemic inflammation, or other tumor-mediated effects. Hypercatabolism due to systemic inflammation can be assessed using serum CRP levels (Moses et al., 2009). Indirect indices of catabolism include responsiveness to chemotherapy and rate of disease progression.
Cancer cachexia is characterized by ongoing skeletal muscle loss. There are various methods for muscle mass assessment: cross-sectional imaging with computed tomography (CT) or magnetic resonance imaging (MRI); appendicular skeletal muscle index obtained from DEXA; mid-upper-arm muscle area by anthropometry; and whole body fat-free mass index determined by bioimpedance analysis (Simons et al., 1995; Prado et al., 2009; Fearon et al., 2011; Di Sebastiano and Mourtzakis, 2012). Imaging-based methods of muscle mass assessment can quantify changes in body composition, including skeletal muscle wasting, altered distribution of body fat, and pathological accumulation of lipids in various tissues. MRI can measure the volume of the quadriceps muscle with a coefficient of variation $<1 \%$. Diagnostic CT scans can be used to estimate abdominal muscle cross-sectional area at the L3 level, which can be extrapolated to whole body lean body mass. These modalities are usually reserved for research purposes and not routinely used in the clinic.

A comprehensive approach, including history, physical examination, and various imaging studies can aid in recognizing the phenomenon termed sarcopenic obesity or cachexia hidden in the context of obesity. Even at the time of diagnosis, approximately $40 \%$ of overweight or obese pancreatic cancer patients have substantial ongoing skeletal muscle wasting (Tan et al., 2009). Early detection of sarcopenic obesity is important because it has been shown to be an independent prognostic factor for decreased survival in pancreatic cancer patients (Tan et al., 2009).

Cancer cachexia can have a profound adverse effect on physical and psychosocial functioning. Patients report altered body images, which can significantly impact emotions and relationships. The method of choice for evaluating functional effects of cancer cachexia is the routine use of patient-reported physical functioning. This assessment can be obtained using the European Organization for Research and Treatment of Cancer (EORTC) Quality of Life Questionnaire (QLQ)-C30 or the Eastern Cooperative Oncology Group (ECOG) questionnaire. Physician-reported physical activity (Karnofsky performance score) and objective methodologies such as electric activity meters or checklists of specific activities can also be used to assess physical functioning. A recent study with subjects wearing an electric activity monitor showed that the level of physical activity in cachectic cancer patients is reduced by about $40 \%$ (Dahele et al., 2007).

\section{MECHANISMS OF CANCER CACHEXIA}

The pathophysiology of cancer cachexia is characterized by negative protein and energy balance driven by a combination of reduced food intake and increased metabolism (Fearon, 2008, 2012; Fearon et al., 2011). This process involves complex interactions between the host and the tumor (Figure 1). There are mechanical factors that contribute to reduced food intake. There is evidence that anorexia and hypercatabolism are driven by cytokines, circulating hormones, neuropeptides, neurotransmitters, and tumor-derived factors. In addition, recent studies have discovered other potentially significant processes involved in pancreatic cancer cachexia, including neural invasion and abnormalities in the muscle microenvironment. This section will review 


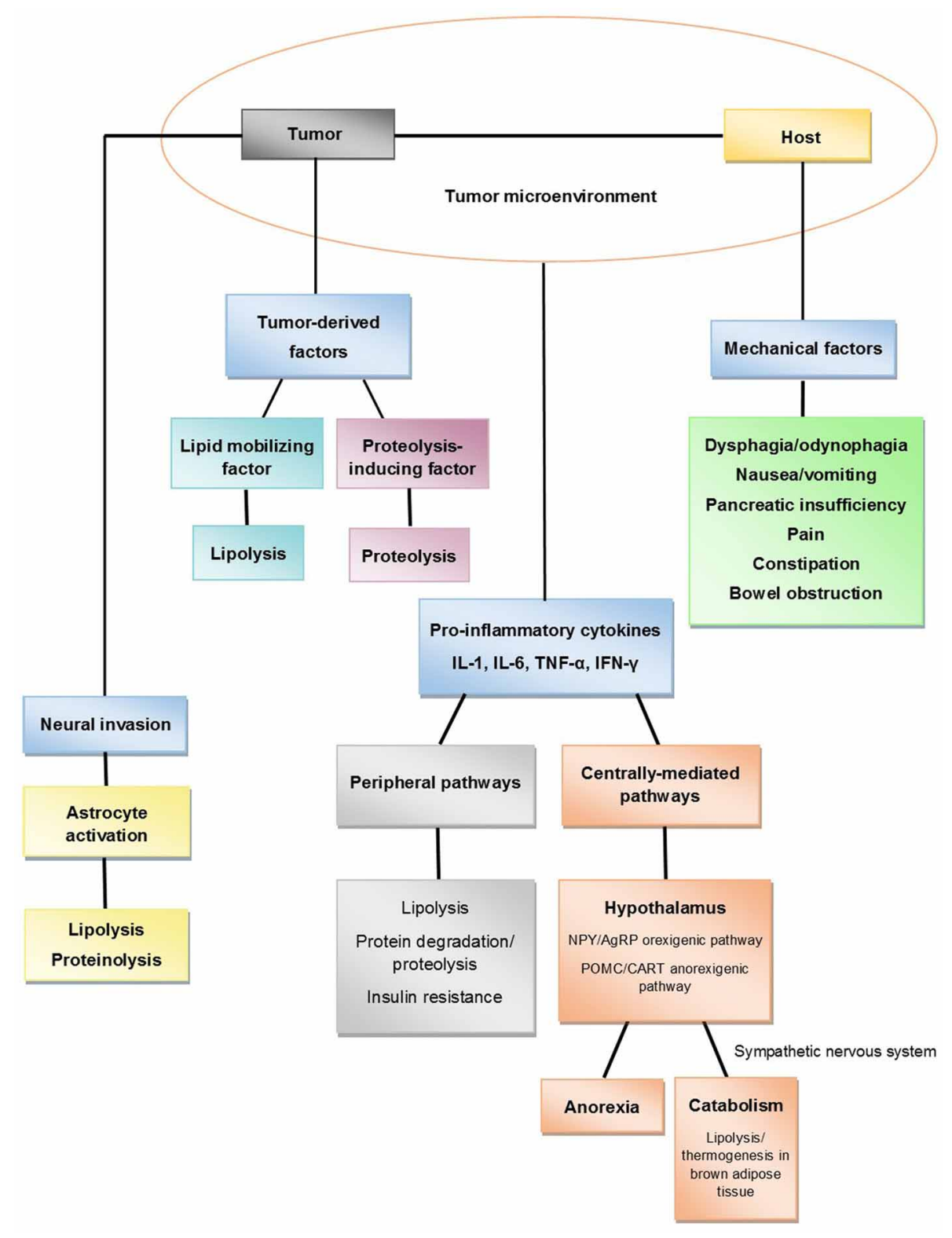

FIGURE 1 | Proposed mechanisms of pancreatic cancer cachexia.

current proposed mechanisms that lead to the development of this disease process.

\section{MECHANICAL FACTORS}

Reduced food intake can promote and maintain cancer-associated weight loss (Wigmore et al., 1997b). Mechanical digestive abnormalities can result in a lack of appetite and reduced food intake. Patients with pancreatic cancer suffer from pain, fatigue, nausea, dysphagia, gastroparesis, duodenal stenosis, pancreatic insufficiency and malabsorption, and constipation (Deutsch and Kolhouse, 2004). These symptoms are the direct consequence of tumor invasion, which can result in the obstruction of the pancreatic duct and/or GI tract, particularly the second portion of the duodenum. Many patients will undergo pancreaticoduodenectomy for the resection of a pancreatic head mass. This procedure can worsen pancreatic insufficiency and decrease oral intake.

\section{CYTOKINES AND SYSTEMIC INFLAMMATION}

Systemic inflammation plays an important role in the pathophysiology of pancreatic cancer cachexia. Elevated CRP levels (CRP $>10 \mathrm{mg} / \mathrm{L})$, an indirect measure of systemic inflammation, has been associated with cachexia and poor prognosis in pancreatic cancer patients (Fearon et al., 2006b). Elevated cytokine levels, including IL-6 and IL-10, have been associated with poor performance, weight loss, and decreased survival in pancreatic 
cancer patients (Ebrahimi et al., 2004; Moses et al., 2009). Recent evidence strongly suggest that cytokines produced by tumor cells or released by the host as a response to the cancer affect various pathways that lead to anorexia and a hypercatabolic state (Figure 1). These pathways can be divided into central pathways, which are hypothalamus-mediated, and peripheral pathways, which involve direct lipolysis and proteolysis.

\section{Centrally-mediated pathways}

Under normal conditions, energy homeostasis is a highly regulated system of controls. The hypothalamus controls energy intake by integrating peripheral signals that convey information on energy and adiposity status. These inputs are transduced into neuronal responses and, via signaling pathways, behavioral responses. Current evidence suggests that systemic inflammation plays a critical role in inducing cancer anorexia by triggering a complex neurochemical cascade (Laviano et al., 2003; Fearon et al., 2013; Suzuki et al., 2013; Tuca et al., 2013). Increased cytokine expression from tumor growth prevents the hypothalamus from responding appropriately to peripheral signals by persistent stimulation of anorexigenic pathways and inhibition of orexigenic pathways (Suzuki et al., 2013; Tuca et al., 2013).

Cancer anorexia may be partially due to derangement of peripheral signaling transduction into neuronal responses by the hypothalamus. There are two pathways that control energy expenditure and food intake within the hypothalamus: neuropeptide $\mathrm{Y}(\mathrm{NPY}) /$ Agouti-related peptide (AgRP) neurons that stimulate energy intake and pro-opiomelanocortin (POMC)/cocaine and amphetamine-regulated transcript (CART) neurons that inhibit intake. Some studies suggest that cancer cachexia is associated with hyperactivation of the POMC/CART pathway which may be triggered by IL-1 and other pro-inflammatory cytokines (Wisse et al., 2001; Marks and Cone, 2003; Marks et al., 2003; Scarlett et al., 2007).

Leptin is a protein involved in regulating energy intake and expenditure. Leptin reduces appetite and increases energy expenditure via the central nervous system (CNS). Through feedback signaling, leptin controls the production, and activation of hypothalamic neuropeptides that regulate food intake and energy expenditure, including NPY and corticotropin-releasing factor (CRF). Since leptin is primarily released by adipose tissue, decreased body fat mass or starvation leads to a decrease in leptin levels. Low leptin levels allow for increased production, release, and action of NPY, a potent orexigenic peptide, which subsequently results in the activation of the NPY/AgRP pathway. Additionally, low leptin levels result in decreased activity of anorexigenic neuropepetides, such as CRF and melanocortin. Studies have demonstrated that cytokines, such as tumor necrosis factor-alpha (TNF- $\alpha$ ) and interleukin1 (IL-1) increase the expression of leptin mRNA in adipocytes and plasma levels of leptin despite starvation (Grunfeld et al., 1996; Janik et al., 1997; Sarraf et al., 1997; Finck et al., 1998). Therefore, an increased leptin level may contribute to cancer anorexia by preventing the normal compensatory mechanisms that should occur with decreased food intake. However, other studies have shown that these cytokines can induce anorexia even in the absence of leptin (Faggioni et al., 1997). Animal and clinical studies have also demonstrated that leptin levels are not elevated in tumor-bearing rats and patients with cancer cachexia (Simons et al., 1997; Wallace et al., 1998; Mantovani et al., 2000; Bing et al., 2001). Recent evidence suggests that in cancer cachexia IL-1 and TNF- $\alpha$ mimic leptin signaling and interfere with the orexigenic response to reduced leptin levels (Inui, 1999; Suzuki et al., 2013). Therefore, even with decreased adiposity, there continues to be suppression of the orexigenic response and stimulation of the anorexigenic pathway, resulting in unopposed anorexia and increased energy expenditure.

Serotonin may also play an important role in the development of cancer anorexia through the melanocortin system. Studies have established that IL-1 stimulates the release of hypothalamic serotonin (Shintani et al., 1993). Elevated serotonin levels, in turn, contribute to the persistent activation of POMC/CART neurons, resulting in decreased appetite and anorexia (Heisler et al., 2002). Studies have demonstrated elevated plasma and cerebrospinal fluid concentrations of tryptophan, a precursor of serotonin, in patients with evidence of cancer cachexia compared to healthy controls or cancer patients without cachexia (Cangiano et al., 1990). Plasma tryptophan concentration normalized, and food intake improved after tumor removal (Cangiano et al., 1994). These findings suggest that hypothalamic serotonin may be an important factor in the pathogenesis of cancer cachexia and a potential therapeutic target.

These hypothalamic pathways and neuropeptides also have catabolic effects. The POMC/CART anorexigenic pathway increases the sympathetic nervous system activity, which causes induction of mitochondrial uncoupling proteins, such as UCP-1 and UCP-2 (Li et al., 2002; Arruda et al., 2010). UCP-1 channels protons across the inner mitochondrial membrane without ATP production, resulting in thermogenesis and energy expenditure in brown adipose tissue (Li et al., 2002; Arruda et al., 2010).

\section{Peripheral pathways}

Cytokines not only corroborate and sustain the neurochemical changes responsible for anorexia, they have also been shown to induce lipolysis, muscle catabolism, and the hepatic acute phase protein response (APPR) through various pathways. These processes lead to the development of uncompensated loss of muscle and adipose tissue mass.

TNF- $\alpha$. TNF- $\alpha$ was first identified as a cachexia-inducing factor in chronic diseases. It may have properties that promote lipolysis, impair lipogenesis, and induce muscle degradation. It has been shown to induce lipolysis in vitro with increases in glycerol release in mouse and human adipocytes, likely through downregulation of perilipin expression (Rydén et al., 2004). Perilipin coats intracellular lipid droplets and acts as a barrier to lipolysis. Decreased perilipin expression subsequently enables hormonesensitive lipase (HSL), a key regulator of lipolysis, to access the surface of lipid droplets for breakdown (Zhang et al., 2002; Rydén et al., 2004). TNF- $\alpha$ also has an inhibitory effect on adipocyte differentiation, resulting in impaired lipogenesis (Cawthorn et al., 2007; Hammarstedt et al., 2007).

Animal studies also suggest that TNF- $\alpha$ is involved in muscle loss in cancer cachexia. Mouse models have shown that TNF- $\alpha$ may induce muscle protein degradation through formation of 
reactive oxygen species (ROS). Oxidative stress results in the activation of nuclear factor $\kappa \mathrm{B}(\mathrm{NF} \kappa \mathrm{B})$ which, in turn, activates the ubiquitin-proteasome pathway (Llovera et al., 1998; Li and Reid, 2000). Moreover, TNF- $\alpha$ has been shown to increase expression of the 1.2- and 2.4-kb transcripts of ubiquitin and the ubiquitin ligase atrogin $1 /$ MAFbx in skeletal muscle (Llovera et al., 1998; Li and Reid, 2000). In addition to protein degradation, TNF- $\alpha$ has been shown to inhibit myogenesis in vitro through $\mathrm{NF} \kappa \mathrm{B}$-mediated downregulation of MyoD transcripts (Guttridge et al., 2000).

Although these findings suggest a role for TNF- $\alpha$ in lipolysis and proteolysis, its importance in cancer cachexia is an active area of debate. Results from studies measuring levels of TNF$\alpha$ in patients with cancer cachexia have been conflicting. Some studies have shown detectable levels of TNF- $\alpha$ in the serum of pancreatic cancer patients with TNF- $\alpha$ levels inversely correlating with body weight and BMI; other studies involving patients with advanced cancers have shown no correlation between circulating TNF- $\alpha$ levels, weight loss, and anorexia (Maltoni et al., 1997; Karayiannakis et al., 2001; Rydén et al., 2008). Therefore, the origin and relevance of TNF- $\alpha$ to cancer cachexia remains unclear.

IL-6. IL-6 is another important cytokine in pancreatic cancer cachexia. IL-6 secretion is induced by TNF- $\alpha$; it acts synergistically with TNF- $\alpha$ in many of its actions including stimulation of other cytokines. Circulating levels of IL- 6 correlate with weight loss and reduced survival in pancreatic cancer patients (Ebrahimi et al., 2004; Martignoni et al., 2005; Moses et al., 2009). Although the role of IL- 6 in lipolysis is not well established, a recent study has shown enhanced IL-6 signaling in brown adipose tissue in cachectic tumor-bearing mice suggesting that it may play a direct role in the activation of thermogenesis (Tsoli et al., 2012). More importantly, IL-6 is known to activate the hepatic APPR and trigger tissue catabolism. The murine C-26 cachexia model has shown that increasing levels of IL-6 correlated with the development of cachexia; treatment with an IL- 6 neutralizing antibody attenuated the development of weight loss (Strassmann et al., 1992). Moses et al. found that pancreatic cancer patients with cachexia had elevated CRP levels and stimulated IL-6 production (Moses et al., 2009). Although various cytokines and hormones affect hepatocyte protein metabolism, IL-6 is known as the principal regulator of APPR in human hepatocytes (Castell et al., 1990). There is a strong correlation between increased peripheral blood mononuclear cells (PBMC) production of IL- 6 and the presence of elevated APPR (Martignoni et al., 2005, 2009; Moses et al., 2009). The activation of hepatic APPR subsequently results in hypercatabolism through reprioritization of body protein metabolism from skeletal muscle to production of acute phase proteins (Fearon et al., 1999). There appears to be a two- to threefold increase in fibrinogen production and increase in serum CRP levels (Preston et al., 1998). Production of these acute phase proteins by the liver is associated with mobilization of peripheral amino acid stores primarily from skeletal muscle contributing to the loss of lean tissue and catabolism. Overproduction of IL-6 and elevated APPR have been associated with decreased survival in patients with pancreatic cancer cachexia (Moses et al., 2009).

\section{TUMOR-DERIVED FACTORS}

In addition to cytokines and systemic inflammation, tumorderived factors contribute to metabolic abnormalities that give rise to pancreatic cancer cachexia. Two of the most well studied factors are lipid mobilizing factor (LMF) and proteolysisinducing factor (PIF). The presence and role of other factors that contribute to pancreatic cancer cachexia are currently being investigated.

\section{Lipid mobilizing factor}

Todorov et al. isolated a LMF from a cachexia-inducing murine tumor (MAC16 adenocarcinoma) model and the urine of patients with unresectable pancreatic cancer and weight loss (Todorov et al., 1998). The material was $43 \mathrm{kDA}$ and was found to be homologous with the plasma protein zinc- $\alpha 2$ glycoprotein (ZAG) (Todorov et al., 1998). Pancreatic cancer patients with weight loss generally had LMF/ZAG in the urine, but it was absent from patients without weight loss or normal subjects (Todorov et al., 1998). A recent study identifying serum proteins involved in pancreatic cancer cachexia identified LMF/ZAG as a possible marker (Felix et al., 2011). Moreover, immunohistochemical analysis demonstrated LMF/ZAG expression in pancreatic cancer cells and in the peritumoral stroma (Felix et al., 2011). Patients with cachexia had stronger immunostaining compared to pancreatic cancer patients without cachexia or normal subjects (Felix et al., 2011).

In vivo studies have shown that LMF/ZAG causes selective loss of carcass fat without change in body water or nonfat mass (Hirai et al., 1998). LMF/ZAG directly induces lipolysis by stimulating adenylate cyclase in a GTP-dependent process; this process is postulated to be mediated by $\beta 3$ adrenergic receptors (Hirai et al., 1998; Khan and Tisdale, 1999; Russell et al., 2002). Hirai et al. showed an increase in serum levels of glycerol and 3hydroxybutyrate after treating mice with LMF/ZAG. They also showed a significant increase in oxygen uptake by brown adipose tissue suggesting that LMF/ZAG promotes lipid utilization (Hirai et al., 1998). In addition, LMF/ZAG has been shown to increase lipid oxidation using the production of ${ }^{14} \mathrm{CO}_{2}$ from $\left[{ }^{14} \mathrm{C}\right.$-carboxy] triolein (Russell and Tisdale, 2002). This function is achieved by directly activating the expression of mitochondrial UCPs. LMF/ZAG induces increased expression of UCP-1, UCP2 , and UCP-3 in brown adipose tissue, and UCP-2 in skeletal muscle and liver (Bing et al., 2002). The effect of LMF/ZAG on lipid oxidation and utilization is also likely mediated by $\beta 3$ adrenergic receptors. LMF/ZAG also increases the sensitivity of white adipose tissues to the lipolytic effects of other stimuli, including catecholamines (Islam-Ali et al., 2001). Adipocyte plasma membranes have Gs $\alpha$-subunits and Gi $\alpha$-subunits, which stimulate and inhibit adenylate cyclase, respectively. LMF/ZAG increases

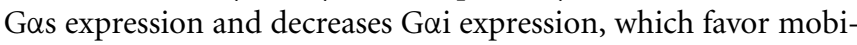
lization of lipid stores from adipocytes and facilitate a catabolic state (Islam-Ali et al., 2001). LMF/ZAG not only increases lipid mobilization through various pathways but it also increases substrate utilization and activates mitochondrial oxidative pathways in brown adipose tissue resulting in lipolysis, increased energy expenditure, and hypercatabolism. 


\section{PROTEOLYSIS-INDUCING FACTOR}

PIF was discovered in 1996 using a MAC16 adenocarcinoma mouse model of cachexia. Todorov et al. reported the discovery of a glycoprotein of molecular mass $24 \mathrm{kDa}$ that produced cachexia in vivo by inducing skeletal muscle catabolism (Todorov et al., 1996). The same material was isolated from urine of cachectic cancer patients, but not from patients with weight loss due to trauma, cancer patients with little or no weight loss, and normal subjects. PIF was detected in the urine of $80 \%$ of pancreatic cancer patients with significantly greater total weight loss and rate of weight loss than patients who did not have PIF in their urine (Wigmore et al., 2000b). Immunochemistry demonstrated that the $24 \mathrm{kDa}$ material is present in the cytoplasm of GI tumors, including pancreatic adenocarcinoma (CabalManzano et al., 2001). Enzymatic degradation of PIF suggests that it consists of a peptide core with molecular weight $4000 \mathrm{Da}$ that is extensively $\mathrm{N}$ - and $\mathrm{O}$-glycosylated to give a total molecular mass of $24 \mathrm{kDa}$ (Todorov et al., 1997). Examination of the sequence of the human genome revealed the gene for the polypeptide core of PIF is located in chromosome 12; two proteins, dermicidin and Y-P30, have been reported to have 100\% homology (Schittek et al., 2001; Cunningham et al., 2002). However, enzymatic degradation has shown that the oligosaccharide chains are essential for the biologic activity of PIF (Todorov et al., 1997).

When administered intravenously to normal mice, PIF isolated from urine of cancer cachexia patients induced cachexia without reduction in food and water intake (Cariuk et al., 1997). Analysis of body composition demonstrated that the majority of weight loss involved loss of lean body mass (Cariuk et al., 1997). This decrease in lean body mass had two components: an increase in protein degradation by $50 \%$ and a decrease in protein synthesis by $50 \%$ observed in gastrocnemius muscle (Lorite et al., 1997). Some studies suggest that PIF-mediated protein degradation may involve the ubiquitin-proteasome proteolytic pathway. Administration of PIF to normal mice caused an increase in mRNA levels for ubiquitin, E2 $14 k$ and the C9 proteasome subunit. Therefore, protein degradation likely occurs through increased expression of the ubiquitin-proteosome pathway in skeletal muscle; this process is thought to be mediated by the activation of NFkB (Lorite et al., 2001; Whitehouse and Tisdale, 2003; Wyke and Tisdale, 2005). PIF has also been shown to induce total protein degradation and myosin depletion while actin levels remain unchanged (Wyke and Tisdale, 2005).

The mechanism for NFKB activation by PIF is not fully understood. It does involve release of arachidonic acid from membrane phospholipids with rapid metabolism to eicosanoids by phospholipase $\mathrm{A}_{2}\left(\mathrm{PLA}_{2}\right)$ (Smith and Tisdale, 2003). PIF has been shown to increase expression of $\mathrm{PLA}_{2}$ (Smith and Tisdale, 2003). One of the eicosanoids formed in response to PIF, 15-hydroxyeicosatetraenoic acid (15-HETE), can induce muscle degradation in murine muscle cells (Wyke et al., 2005). 15HETE may be involved in the activation of protein kinase $\mathrm{C}$ (PKC), which is important in the activation of NADPH oxidase (Whitehouse et al., 2003; Smith et al., 2004; Wyke et al., 2005). Activation of NADPH oxidase and generation of ROS play a key role in PIF-induced expression of the ubiquitin-proteasome pathway leading to muscle degradation (Smith et al., 2004; Russell et al., 2007). Increased ROS activates IкB kinase (IKK) which leads to phosphorylation and degradation of I $\mathrm{B}$; this process, in turn, releases NFкB from its inactive cytosolic complex (Smith et al., 2004).

PIF not only results in protein degradation, it also causes inhibition of protein synthesis. PIF induces the activation/phosphorylation of double-stranded RNA-dependent protein kinase (PKR) (Eley and Tisdale, 2007). The activation of PKR leads to the phosphorylation of eIF2, which inhibits translation initiation and protein synthesis (Eley and Tisdale, 2007). In addition, PKR is known to activate IKK resulting in the nuclear accumulation of NFKB and increased expression and activity of the ubiquitin-proteasome pathway (Zamanian-Daryoush et al., 2000).

In addition to its direct effects on skeletal muscles, PIF may play a role in increasing hepatic cytokine production. Treatment of cultures of human hepatocytes with PIF resulted in activation of $\mathrm{NF \kappa B}$ and signal transducers and activators of transcription (STAT3), which caused an increased production of IL-6, IL-8, and CRP, as well as decreased production of transferrin (Watchorn et al., 2001). A similar effect was observed in human Kupffer cells and monocytes and resulted in increased production of TNF- $\alpha$, IL-6, and IL-8 (Watchorn et al., 2005). PIF may likely contribute to APPR seen in pancreatic cancer cachexia.

\section{OTHER PROPOSED MECHANISMS Pax7 dysregulation}

A recent study provides evidence for a different pathway involved in pancreatic cancer related muscle wasting. Pax7 is a self-renewing transcription factor expressed in various muscle cells, including satellite cells and other myogenic progenitor cells. He et al. demonstrated that NFKB activation in satellite cells resulted in the dysregulation of Pax7, which suppressed expression of MyoD and myogenin (Olguin and Olwin, 2004; He et al., 2013). This process subsequently blocked myogenic differentiation and inhibited myoblast fusion leading to impaired regeneration and muscle wasting ( $\mathrm{He}$ et al., 2013). They also demonstrated that Pax7 was induced by serum factors from cachectic mice and pancreatic cancer patients in an NFKB-dependent manner both in vitro and in vivo (He et al., 2013). However, it remains unclear what circulating factors lead to NFאB activation and Pax7 dysregulation.

\section{Neural invasion}

Recent studies have shown that neural invasion, which commonly occurs in pancreatic cancer, is related to cachexia and astrocyte activation in pancreatic cancer patients (Mitsunaga et al., 2008; Imoto et al., 2012). Nerve damage from intraneural tumors of pancreatic cancer can activate astrocytes and microglia in the spinal cord. These activated astrocytes subsequently induce lipolysis and muscle atrophy, although the mechanisms leading to cachexia require further investigation (Imoto et al., 2012). These activated astrocytes may increase sympathetic nervous system activity, which is known to cause lipolysis in adipose tissue and muscle atrophy (Li et al., 2002). 


\section{MANAGEMENT OF CANCER CACHEXIA}

Clinical management of cachexia is currently limited and complex. Best supportive care practices are important in managing secondary causes of anorexia including pain, nausea, pancreatic insufficiency, and constipation. In addition, current treatment strategies are based on the following factors: oncological therapy with optimal control of the tumor; nutritional support; and pharmacological treatment. Since cancer cachexia is a multifactorial syndrome, successful treatment will likely involve a multimodal approach.

\section{NUTRITIONAL SUPPORT}

Nutritional risk is highest among pancreatic cancer patients (Bozzetti and Group, 2009). Early involvement of dieticians and nutrition assessment programs are essential to guide management. Nutritional support is an integral part of pancreatic cancer cachexia management and involves providing dietary advice, oral nutritional supplementation, enteral nutrition, and parenteral nutrition (Ottery, 1996; Nitenberg and Raynard, 2000; Jatoi and Loprinzi, 2001; el-Kamar et al., 2003).

Dietary recommendations can significantly increase oral caloric and protein intake (Ovesen et al., 1993). Several studies evaluating the role of oral nutritional supplementation among patients with pancreatic cancer demonstrated improvement in weight and appetite (Fearon et al., 2003; Bauer and Capra, 2005). Oral supplementation with compounds such as L-Carnitine and omega-3 fatty acids may have benefits as well (Barber et al., 1999; Kraft et al., 2012). A small multicenter randomized double-blind trial demonstrated a significant improvement in weight and body mass composition as well as quality of life with L-Carnitine supplementation in patients with advanced pancreatic cancer (Kraft et al., 2012).

In patients with swallowing difficulties or severe dysphagia, a complete enteral diet can be administered using a nasogastric tube or gastrostomy tube. Enteral feeding can be associated with significant morbidity due to aspiration, pneumonia, and diarrhea. In a select group of patients with bowel dysfunction and progressive weight loss despite enteral support, parenteral nutrition may provide a temporary benefit or stabilization in nutritional status (Pelzer et al., 2010).

Artificial nutrition can limit nutritional deterioration in cachectic cancer patients and improve certain metabolic and nutritional indices. However, the nutritional response is typically limited. It is also lower than responses observed in malnourished non-cancer patients receiving equivalent artificial nutrition (Nixon et al., 1981). Patients with pancreatic cancer cachexia require a multimodal approach to disease management (DeWys, 1979).

\section{PHARMACOLOGICAL APPROACH}

Various drugs have been studied in the treatment of cancer cachexia. Their mechanisms of action are based on modulation of cytokines, hormones, or other pathways involved in the pathophysiology of cancer cachexia. Table 3 summarizes drugs and their pharmacologic activity with proven or potential effects on pancreatic cancer cachexia.

\section{Progestogens}

Megestrol acetate is a semi-synthetic progesterone currently used as an appetite stimulant. When megestrol acetate was first introduced in the treatment of disseminated breast and endometrial cancer, patients developed weight gain and increased appetite as a side effect. Multiple trials demonstrated that megestrol acetate $(480-800 \mathrm{mg} /$ day) resulted in significant improvement in appetite, food intake, nausea, and weight gain among patients with cancer cachexia, including those with pancreatic cancer (Bruera et al., 1990; Loprinzi et al., 1990, 1993a; Westman et al., 1999; Deutsch and Kolhouse, 2004). In 1993, the Food and Drug Administration (FDA) approved megestrol acetate for the treatment of cancer anorexia-cachexia syndrome as well as cachexia due to chronic conditions, including human acquired immunodeficiency syndrome (AIDS). Megestrol acetate is typically well-tolerated with low incidence of adverse effects, such as rash, adrenal insufficiency, hyperglycemia, and thromboembolic events. The increase in thromboembolism has an incidence of less than 5\% (Loprinzi et al., 1990). Since its approval, various metaanalyses have confirmed that megestrol acetate increases appetite, weight, and quality of life compared to placebo or other drugs potentially active in the management of cancer cachexia (cisapride, dronabinol, corticosteroids, nandrolone) (Pascual López et al., 2004; Leśniak et al., 2008). The efficacy of megestrol acetate appears to be dose-dependent (Loprinzi et al., 1993a). Based on body composition analysis, megestrol acetate causes weight gain predominantly from an increase in adipose tissue and less from an increase in body fluid (Loprinzi et al., 1993b). There was no improvement in survival demonstrated in patients treated with megestrol acetate (Westman et al., 1999; Leśniak et al., 2008).

The pharmacologic activity of megestrol acetate in appetite stimulation and weight gain may be related to decreased production and release of pro-inflammatory cytokines (IL-1, IL-6, TNF- $\alpha$ ) and stimulation of NPY in the hypothalamus (McCarthy et al., 1994; Mantovani et al., 1998a,b). Another progestogen, medroxyprogesterone acetate, was shown to decrease in vitro production of cytokines and serotonin by PBMC of cancer patients (Mantovani et al., 1998a,b).

\section{Corticosteroids}

Corticosteroids are effective in inducing an increase in appetite, food intake, weight gain, and sense of well-being (Willox et al., 1984; Bruera et al., 1985; Loprinzi et al., 1999). However, the effects are short lived (less than 4 weeks) and associated with long-term side effects, such as insulin resistance, fluid retention, steroid-induced myopathy, skin fragility, adrenal insufficiency, and sleep and cognitive disorders (Loprinzi et al., 1999). The mechanism of action in cancer cachexia is not well understood but is likely related to the inhibition of IL-1, TNF- $\alpha$, and leptin as well as the stimulation of NPY (Plata-Salamán, 1991). Because of their short term symptomatic benefits but long term adverse effects, corticosteroids may be useful in patients with short expected survival.

\section{Cannabinoids}

Dronabinol is effective in reducing nausea and increasing appetite with associated weight stabilization. A phase II trial showed that 
Table 3 | Pharmacological approach to pancreatic cancer cachexia.

\begin{tabular}{|c|c|c|c|}
\hline Drugs & Mechanism of action & References & $\begin{array}{l}\text { Level of } \\
\text { evidence }\end{array}$ \\
\hline $\begin{array}{l}\text { Progestogens } \\
\text { (megestrol acetate and } \\
\text { medroxyprogesterone acetate) }\end{array}$ & $\begin{array}{l}\text { Appetite stimulation } \\
\text { Decrease production and release of cytokines (IL-1, } \\
\text { IL-6, TNF- } \alpha \text { ) } \\
\text { Stimulation of NPY } \\
\text { Decrease production of serotonin in PBMC }\end{array}$ & $\begin{array}{l}\text { Bruera et al., 1990; Loprinzi et al., 1990, } \\
\text { 1993a,b; McCarthy et al., 1994; Mantovani } \\
\text { et al., 1998a,b; Westman et al., 1999; } \\
\text { Deutsch and Kolhouse, 2004; Pascual } \\
\text { López et al., 2004; Leśniak et al., } 2008\end{array}$ & I \\
\hline $\begin{array}{l}\text { Cannabinoids } \\
\text { (dronabinol) }\end{array}$ & $\begin{array}{l}\text { Appetite stimulation, anti-emetic } \\
\text { Interaction with endorphin receptors } \\
\text { Interference with IL-1 synthesis } \\
\text { Activation of cannabinoid receptor involved in the } \\
\text { neurochemical circuit of leptin } \\
\text { Inhibition of prostaglandin synthesis }\end{array}$ & Nelson et al., 1994; Jatoi et al., 2002 & $\|$ \\
\hline $\begin{array}{l}\text { NSAIDs } \\
\text { (COX-2 inhibitors, indomethacin, } \\
\text { ibuprofen) }\end{array}$ & $\begin{array}{l}\text { Anti-inflammatory } \\
\text { Decrease production and release of acute phase } \\
\text { proteins and pro-inflammatory cytokines } \\
\text { Inhibit prostaglandin synthesis }\end{array}$ & $\begin{array}{l}\text { Gelin et al., 1991a,b; Lundholm et al., } \\
\text { 1994; McMillan et al., 1995, 1997, 1999; } \\
\text { Preston et al., 1995; Wigmore et al., 1995; } \\
\text { Lai et al., } 2008\end{array}$ & II \\
\hline Thalidomide & $\begin{array}{l}\text { Anti-inflammatory and immunomodulatory } \\
\text { properties } \\
\text { Downregulate production of TNF- } \alpha \text { and other } \\
\text { cytokines } \\
\text { Inhibit NFKB } \\
\text { Downregulate COX-2 } \\
\text { Inhibit angiogenesis }\end{array}$ & $\begin{array}{l}\text { Sampaio et al., 1991; Bruera et al., 1999; } \\
\text { Gordon et al., } 2005\end{array}$ & ॥ \\
\hline
\end{tabular}

NSAIDs, non-steroidal anti-inflammatory drugs; NPY, neuropeptide $Y$; IL-1, interleukin-1; IL-6, interleukin-6; TNF- $\alpha$, tumor necrosis factor-alpha; PBMC, peripheral blood mononuclear cells; NFKB, nuclear factor $\mathrm{\kappa} B$; COX-2, cyclooxygenase-2; LMF, lipid mobilizing factor; PIF, proteolysis-inducing factor.

dronabinol reduced anorexia in $68 \%$ of patients, but $16 \%$ of patients had to suspend treatment due to toxicity (Nelson et al., 1994). Dronabinol has many adverse effects on the CNS. The main side effects include euphoria, hallucinations, psychosis, vertigo, and cardiovascular disorders. Appetite stimulation appears to be mediated by interaction with endorphin receptors, interference with IL-1 synthesis, activation of cannabinoid receptors involved in the neurochemical circuit of leptin, and prostaglandin synthesis inhibition.

A controlled clinical trial by Jatoi et al. compared megestrol acetate and dronabinol in patients with cancer cachexia (Jatoi et al., 2002). A total of 469 patients were treated with megestrol acetate $800 \mathrm{mg} /$ day or dronabinol $2.5 \mathrm{mg} / 12 \mathrm{~h}$ or both. There was a greater increase in appetite and weight in the megestrol acetate group compared to the dronabinol group: 75 vs. $49 \%$ $(P=0.0001)$ for appetite, respectively and 11 vs. $3 \%(P=0.02)$ for weight gain of at least $10 \%$ from baseline, respectively (Jatoi et al., 2002). The combination treatment group resulted in no significant differences in appetite and weight when compared to the megestrol acetate only group ( 66 vs. $75 \%, P=0.17$, for appetite and 8 vs. $11 \%, P=0.43$, for $=10 \%$ weight gain, respectively). Megestrol acetate appears to be superior to dronabinol although the cannabinoid is still able to trigger an increase in appetite and reduction in nausea. It serves as an alternative option as an appetite stimulant and anti-emetic.

\section{Anti-inflammatory agents}

Systemic inflammation is an important contributor to the pathophysiology of pancreatic cancer cachexia. Pro-inflammatory cytokines, such as TNF- $\alpha$, IL-1, and IL-6, have been implicated in the development of cancer cachexia and have been shown to exhibit synergistic effects. Therefore, multiple therapeutic 
strategies have been developed to curtail the inflammatory response by blocking the synthesis or action of cytokines.

Non-steroidal anti-inflammatory drugs (NSAIDs), including cyclooxygenase-2 (COX-2) inhibitors, indomethacin, and ibuprofen, reduce release of acute phase proteins and cytokines (McMillan et al., 1995; Preston et al., 1995; Wigmore et al., 1995). In animal studies, inhibition of prostaglandin synthesis attenuated tumor progression and decreased incidence of cancer cachexia (Gelin et al., 1991a,b). One possible explanation is that cytokines depend on signal transduction mediated by eicosanoids; NSAIDs inhibit prostaglandin synthesis and thereby block downstream effects of systemic inflammation. Lundholm et al. demonstrated that indomethacin use may prolong survival in cachectic patients with metastatic solid tumors, including pancreatic cancer (Lundholm et al., 1994). Other controlled clinical trials have shown that ibuprofen can decrease CRP levels, increase body weight and muscle mass, and improve quality of life, especially when combined with progestogens (Wigmore et al., 1995; McMillan et al., 1997; Lai et al., 2008). McMillan et al. recruited 73 patients with advanced GI cancers, predominantly pancreatic cancer (67\% of patients), and cancer cachexia (McMillan et al., 1999). This multicenter randomized controlled trial demonstrated that taking ibuprofen ( $1200 \mathrm{mg} /$ day) combined with megestrol acetate $(480 \mathrm{mg} /$ day $)$ resulted in a significant increase in weight and improved quality of life compared to patients taking megestrol acetate alone (McMillan et al., 1999). Observed side effects were similar in both groups including venous thrombosis, upper GI bleeding, and ascites. However, due to disease progression, the attrition rate was quite high with $63 \%$ of patients failing to complete the 12 -week assessment. These preliminary results are promising, but further larger studies are needed to evaluate the clinical role of NSAIDs in the management of pancreatic cancer cachexia.

Thalidomide is known to have anti-inflammatory and immunomodulatory properties. It has been shown to downregulate the production of TNF- $\alpha$ and other cytokines, inhibit NFKB, downregulate COX-2, and inhibit angiogenesis (Sampaio et al., 1991). Multiple small studies have demonstrated the efficacy of thalidomide in improving appetite, weight gain, and sensation of well-being (Bruera et al., 1999; Gordon et al., 2005). Gordon et al. reports a single-center double-blind placebo-controlled randomized clinical trial of thalidomide in 50 pancreatic cancer patients with cachexia. Patients were randomized to take thalidomide $200 \mathrm{mg} /$ day or placebo. Patients in the thalidomide group compared to the placebo group had a significant improvement in weight $(0.37$ vs. $-2.21 \mathrm{~kg}, P=0.005)$ and lean body mass $\left(1.0 \mathrm{~cm}^{3}\right.$ in arm muscle mass vs. $\left.-4.46 \mathrm{~cm}^{3}, P=0.002\right)$ after 4 weeks (Gordon et al., 2005). Thalidomide was overall well-tolerated. Adverse reactions included peripheral neuropathy, dizziness, somnolence, constipation, rash, and possible increased risk of venous thromboembolism in the setting of malignancy. These initial results are positive but further clinical trials are needed to confirm the efficacy of thalidomide in treating pancreatic cancer cachexia.

The omega-3 fatty acids, eicosapentaenoic acid (EPA) and docosahexaenoic acid (DHA), are known to have immunomodulatory properties and have been shown to suppress production of pro-inflammatory cytokines, including IL-1, TNF- $\alpha$, and IL-6 by PBMC (Meydani et al., 1993; Wigmore et al., 1997a). EPA may also inhibit the downstream effects of LMF and PIF (Tisdale and Beck, 1991; Tisdale, 1996; Hussey and Tisdale, 1999). Early studies associated fish oil supplementation containing both EPA and DHA as well as high-purity EPA administration with weight stabilization in patients with unresectable pancreatic cancer (Wigmore et al., 1996, 2000b). A small pilot study also showed that the use of EPA with oral nutritional supplements resulted in significant increase in weight, dietary intake, and performance status in cachectic patients with advanced pancreatic cancer (Barber et al., 1999). However, recent data from a multicenter doubleblind placebo-controlled randomized clinical trial suggest that single agent EPA administration is not effective in treating cancer cachexia (Fearon et al., 2006a). Another multicenter clinical trial comparing the effects of EPA supplement, megestrol acetate, and combination treatment found that megestrol acetate alone is more effective than EPA in increasing weight (Jatoi et al., 2004). EPA was comparable to megestrol acetate with respect to appetite gain, survival, and quality of life (Jatoi et al., 2004). Combination therapy did not have additional benefits to megestrol acetate alone (Jatoi et al., 2004). The role of EPA in cancer cachexia management remains uncertain although recent data suggest that EPA supplementation may not be effective as a single agent or even in combination regimens in the management of pancreatic cancer cachexia.

Pancreatic cancer cachexia is a complex multifactorial syndrome. Successful management may require a multimodal approach with nutritional supplementation and pharmacological treatment. Recent data from a large multicenter trial suggest that combination therapy with megestrol acetate $(320 \mathrm{mg} /$ day $)$, EPA supplementation, L-carnitine (4 g/day), and thalidomide ( $200 \mathrm{mg} /$ day) is significantly more effective in improving lean body mass and appetite than single agents (Mantovani et al., 2010). Combination pharmacological therapy with nutritional supplementation in the context of best supportive care may be the appropriate approach to pancreatic cancer cachexia management.

\section{FUTURE DIRECTIONS}

Current clinical management of pancreatic cancer cachexia is limited. None of the available therapies have shown lasting effects on weight stabilization and improvement in survival. Development of effective treatment for this disease remains a challenge.

Recent studies have focused on targeted therapies with antiinflammatory properties (Table 4). IL-6 is a promising target, but many of the studies involving IL- 6 antibodies have been in patients with advanced non-small cell lung cancer (NSCLC) and cachexia (Rigas et al., 2010; Schuster et al., 2010; Bayliss et al., 2011; Ando et al., 2013). Rigas and Schuster et al. reported a phase II randomized, double-blind, placebo-controlled trial with NSCLC patients evaluating the safety and efficacy of ALD518 (also known as BMS-945429), a humanized monoclonal IL-6 antibody, in treating cancer cachexia. ALD518 showed promising beneficial results. It increased hemoglobin levels and prevented loss of lean body mass (Rigas et al., 2010; Schuster et al., 2010). There was also a statistically significant improvement in fatigue score in the ALD518 group vs. placebo group that persisted over 
Table 4 | Investigational drugs for the treatment of cancer cachexia.

\begin{tabular}{|c|c|c|c|c|c|}
\hline $\begin{array}{l}\text { ClinicalTrials. } \\
\text { gov identifier }\end{array}$ & Title & Phase & $\begin{array}{l}\text { Mechanism of } \\
\text { action }\end{array}$ & Sponsor & References \\
\hline NCT01206335 & $\begin{array}{l}\text { Open label study with } \\
\text { OHR/AVR118 in } \\
\text { advanced cancer patients } \\
\text { with anorexia-cachexia }\end{array}$ & II & $\begin{array}{l}\text { Broad spectrum } \\
\text { peptide-nucleic acid } \\
\text { immunomodulator targeting } \\
\text { cytokine production } \\
\text { (including TNF- } \alpha \text { and IL-6) }\end{array}$ & $\begin{array}{l}\text { Ohr Pharmaceutical } \\
\text { Inc. }\end{array}$ & $\begin{array}{l}\text { ClinicalTrials.gov. Open } \\
\text { label study with } \\
\text { OHR/AVR118 in } \\
\text { advanced cancer } \\
\text { patients with } \\
\text { anorexia-cachexia }\end{array}$ \\
\hline NCT01433263 & $\begin{array}{l}\text { Clinical study BYM338 } \\
\text { for the treatment of } \\
\text { unintentional weight loss } \\
\text { in patients with cancer of } \\
\text { the lungs or the pancreas }\end{array}$ & $\|$ & $\begin{array}{l}\text { Human monoclonal } \\
\text { antibody against activin } \\
\text { receptor type } 2 \mathrm{~B} \text { (ACVR2B) }\end{array}$ & $\begin{array}{l}\text { Novartis } \\
\text { Pharmaceuticals }\end{array}$ & $\begin{array}{l}\text { ClinicalTrials.gov. } \\
\text { Clinical study of } \\
\text { BYM338 for the } \\
\text { treatment of } \\
\text { unintentional weight } \\
\text { loss in patients with } \\
\text { cancer of the lung or } \\
\text { the pancreas }\end{array}$ \\
\hline NCT01505530 & $\begin{array}{l}\text { A phase } 2 \text { study of } \\
\text { LY2495655 in participants } \\
\text { with pancreatic cancer }\end{array}$ & $\|$ & $\begin{array}{l}\text { Humanized monoclonal } \\
\text { antibody against myostatin }\end{array}$ & Eli Lilly and Company & $\begin{array}{l}\text { ClinicalTrials.gov. A } \\
\text { Phase } 2 \text { study of } \\
\text { LY2495655 in } \\
\text { participants with } \\
\text { pancreatic cancer }\end{array}$ \\
\hline
\end{tabular}

a 12 week period (Rigas et al., 2010). ALD518 was safe and well-tolerated (Rigas et al., 2010; Schuster et al., 2010).

Another agent with anti-inflammatory activity is OHR/AVR118, a broad-spectrum peptide-nucleic acid immune modulator that targets both TNF- $\alpha$ and IL-6. A phase II study involving patients with advanced cancer and cachexia showed an improvement in anorexia, dyspepsia, strength, and depression (Chasen et al., 2011). A phase IIb study is currently ongoing to assess the efficacy of OHR/AVR118 in improving appetite and enhancing weight, lean body mass, strength, and quality of life (ClinicalTrials.gov. Open label study with OHR/AVR118 in advanced cancer patients with anorexia-cachexia). Further studies are needed to evaluate the safety and efficacy of these agents in patients with pancreatic cancer cachexia.

Myostatin and activin are involved in regulating skeletal muscle mass and function via the activin type IIB (ActRIIB) receptor. They inhibit myogenesis and the Akt/mTOR pathway involved in muscle protein synthesis and increase the expression of ubiquitin ligases to increase muscle degradation. Studies have investigated the therapeutic potential of inhibiting myostatin and ActRIIB in treating cancer cachexia. In pre-clinical studies, inhibition of ActRIIB prevented muscle wasting and prolonged survival in C-26 tumor-bearing mice (Zhou et al., 2010). BYM338 is a myostatin inhibitor developed by Novartis (Hanover, NJ, USA) to treat cancer cachexia. A multicenter, randomized, doubleblind, placebo-controlled phase II trial is currently underway to investigate the efficacy of BYM338 in attenuating loss of body mass in cachectic patients with stage IV NSCLC or stage III/IV pancreatic cancer (ClinicalTrials.gov. Clinical study of BYM338 for the treatment of unintentional weight loss in patients with cancer of the lung or the pancreas). LY2495655 is another humanized antimyostatin antibody currently under investigation. A multicenter, randomized, double-blind, placebo-controlled phase II trial in patients with locally advanced or metastatic pancreatic cancer is ongoing to evaluate the efficacy of two different doses of LY2495655 in combination with gemcitabine in improving survival as well as lean body mass and physical performance (ClinicalTrials.gov. A Phase 2 study of LY2495655 in participants with pancreatic cancer).

\section{CONCLUSION}

Approximately $80 \%$ of pancreatic cancer patients develop cachexia during the disease course and up to $30 \%$ die from cachexia-related complications (Fearon et al., 2006b; Bachmann et al., 2009). Pancreatic cancer cachexia is a multifactorial syndrome characterized by anorexia and hypercatabolism that are mediated by mechanical factors, pro-inflammatory cytokines, neuropeptides, hormones, and tumor-derived factors. In pancreatic cancer, energy homeostasis is compromised and oriented toward a continuous suppression of appetite and increased energy expenditure. This state leads to uncompensated loss of skeletal muscle and adipose tissue mass.

Further research is needed to elucidate the intricate mechanisms involved in the induction and maintenance of pancreatic cancer cachexia to aid in the development of future therapeutic targets. The management of cachexia remains limited but is currently an active area of research. The use of targeted immunotherapies have shown promising preliminary results. The future management of pancreatic cancer cachexia will likely involve a multimodal approach with nutritional support, combination agents and possible targeted therapies to improve quality of life, lean body mass, and even survival of pancreatic cancer patients. 


\section{REFERENCES}

Ando, K., Takahashi, F., Motojima, S., Nakashima, K., Kaneko, N., Hoshi, K., et al. (2013). Possible role for tocilizumab, an anti-interleukin-6 receptor antibody, in treating cancer cachexia. J. Clin. Oncol. 31, e69-e72. doi: 10.1200/JCO.2012.44.2020

Arruda, A. P., Milanski, M., Romanatto, T., Solon, C., Coope, A., Alberici, L. C., et al. (2010). Hypothalamic actions of tumor necrosis factor alpha provide the thermogenic core for the wastage syndrome in cachexia. Endocrinology 151, 683-694. doi: 10.1210/en.2009-0865

Bachmann, J., Heiligensetzer, M., Krakowski-Roosen, H., Büchler, M. W., Friess, H., and Martignoni, M. E. (2008). Cachexia worsens prognosis in patients with resectable pancreatic cancer. J. Gastrointest. Surg. 12, 1193-1201. doi: 10.1007/s11605-008-0505-Z

Bachmann, J., Ketterer, K., Marsch, C., Fechtner, K., Krakowski-Roosen, H., Buchler, M. W., et al. (2009). Pancreatic cancer related cachexia: influence on metabolism and correlation to weight loss and pulmonary function. BMC Cancer 9:255. doi: 10.1186/1471-2407-9-255

Barber, M. D., Ross, J. A., Voss, A. C., Tisdale, M. J., and Fearon, K. C. (1999). The effect of an oral nutritional supplement enriched with fish oil on weight-loss in patients with pancreatic cancer. Br. J. Cancer 81, 80-86. doi: 10.1038/sj.bjc.6690654

Bauer, J. D., and Capra, S. (2005). Nutrition intervention improves outcomes in patients with cancer cachexia receiving chemotherapy-a pilot study. Support. Care Cancer 13, 270-274. doi: 10.1007/s00520-004-0746-7

Bayliss, T. J., Smith, J. T., Schuster, M., Dragnev, K. H., and Rigas, J. R. (2011). A humanized anti-IL-6 antibody (ALD518) in non-small cell lung cancer. Expert Opin. Biol. Ther. 11, 1663-1668. doi: 10.1517/14712598.2011.627850

Bing, C., Russell, S. T., Beckett, E. E., Collins, P., Taylor, S., Barraclough, R., et al. (2002). Expression of uncoupling proteins-1, -2 and -3 mRNA is induced by an adenocarcinoma-derived lipid-mobilizing factor. Br. J. Cancer 86, 612-618. doi: 10.1038/sj.bjc.6600101

Bing, C., Taylor, S., Tisdale, M. J., and Williams, G. (2001). Cachexia in MAC16 adenocarcinoma: suppression of hunger despite normal regulation of leptin, insulin and hypothalamic neuropeptide Y. J. Neurochem. 79, 1004-1012. doi: 10.1046/j.1471-4159.2001.00639.x

Bozzetti, F., and Group, S. W. (2009). Screening the nutritional status in oncology: a preliminary report on 1,000 outpatients. Support. Care Cancer 17, 279-284. doi: 10.1007/s00520-008-0476-3

Bruera, E., MacMillan, K., Kuehn, N., Hanson, J., and MacDonald, R. N. (1990). A controlled trial of megestrol acetate on appetite, caloric intake, nutritional status, and other symptoms in patients with advanced cancer. Cancer 66, 1279-1282. doi: 10.1002/1097-0142(19900915)66:6\%3C1279::AIDCNCR2820660630\%3E3.0.CO;2-R

Bruera, E., Neumann, C. M., Pituskin, E., Calder, K., Ball, G., and Hanson, J. (1999). Thalidomide in patients with cachexia due to terminal cancer: preliminary report. Ann. Oncol. 10, 857-859. doi: 10.1023/A:1008329821941

Bruera, E., Roca, E., Cedaro, L., Carraro, S., and Chacon, R. (1985). Action of oral methylprednisolone in terminal cancer patients: a prospective randomized double-blind study. Cancer Treat. Rep. 69, 751-754.

Bruera, E., and Sweeney, C. (2000). Cachexia and asthenia in cancer patients. Lancet Oncol. 1, 138-147. doi: 10.1016/S1470-2045(00)00033-4

Cabal-Manzano, R., Bhargava, P., Torres-Duarte, A., Marshall, J., and Wainer, I. W. (2001). Proteolysis-inducing factor is expressed in tumours of patients with gastrointestinal cancers and correlates with weight loss. Br. J. Cancer 84, 1599-1601. doi: 10.1054/bjoc.2001.1830

Cangiano, C., Cascino, A., Ceci, F., Laviano, A., Mulieri, M., Muscaritoli, M., et al. (1990). Plasma and CSF tryptophan in cancer anorexia. J. Neural Transm. Gen. Sect. 81, 225-233. doi: 10.1007/BF01245044

Cangiano, C., Testa, U., Muscaritoli, M., Meguid, M. M., Mulieri, M., Laviano, A., et al. (1994). Cytokines, tryptophan and anorexia in cancer patients before and after surgical tumor ablation. Anticancer Res. 14, 1451-1455.

Cariuk, P., Lorite, M. J., Todorov, P. T., Field, W. N., Wigmore, S. J., and Tisdale, M. J. (1997). Induction of cachexia in mice by a product isolated from the urine of cachectic cancer patients. Br. J. Cancer 76, 606-613. doi: 10.1038/bjc. 1997.433

Castell, J. V., Gómez-Lechón, M. J., David, M., Fabra, R., Trullenque, R., and Heinrich, P. C. (1990). Acute-phase response of human hepatocytes: regulation of acute-phase protein synthesis by interleukin-6. Hepatology 12, 1179-1186. doi: 10.1002/hep.1840120517
Cawthorn, W. P., Heyd, F., Hegyi, K., and Sethi, J. K. (2007). Tumour necrosis factor-alpha inhibits adipogenesis via a betacatenin/TCF4(TCF7L2)-dependent pathway. Cell Death Differ. 14, 1361-1373. doi: $10.1038 /$ sj.cdd.4402127

Chasen, M., Hirschman, S. Z., and Bhargava, R. (2011). Phase II study of the novel peptide-nucleic acid OHR118 in the management of cancer-related anorexia/cachexia. J. Am. Med. Dir. Assoc. 12, 62-67. doi: 10.1016/j.jamda.2010.02.012

ClinicalTrials.gov. A Phase 2 study of LY2495655 in participants with pancreatic cancer. Available online at: http://clinicaltrials.gov/ct2/show/NCT01505530. (Accessed December 2013).

ClinicalTrials.gov. Clinical study of BYM338 for the treatment of unintentional weight loss in patients with cancer of the lung or the pancreas. Available online at: http://clinicaltrials.gov/ct2/show/NCT01433263. (Accessed December 2013)

ClinicalTrials.gov. Open label study with OHR/AVR118 in advanced cancer patients with anorexia-cachexia. Available online at: http://clinicaltrials.gov/ct2/show/ NCT01206335. (Accessed December 2013).

Cunningham, T. J., Jing, H., Akerblom, I., Morgan, R., Fisher, T. S., and Neveu, M. (2002). Identification of the human cDNA for new survival/evasion peptide (DSEP): studies in vitro and in vivo of overexpression by neural cells. Exp. Neurol. 177, 32-39. doi: 10.1006/exnr.2002.7979

Dahele, M., Skipworth, R. J., Wall, L., Voss, A., Preston, T., and Fearon, K. C. (2007). Objective physical activity and self-reported quality of life in patients receiving palliative chemotherapy. J. Pain Symptom Manage. 33, 676-685. doi: 10.1016/j.jpainsymman.2006.09.024

Deutsch, J., and Kolhouse, J. F. (2004). Assessment of gastrointestinal function and response to megesterol acetate in subjects with gastrointestinal cancers and weight loss. Support. Care Cancer 12, 503-510. doi: 10.1007/s00520-004-0615-4

DeWys, W. D. (1979). Anorexia as a general effect of cancer. Cancer 43, 2013-2019. doi: 10.1002/1097-0142(197905)43:5+\%3C2013::AIDCNCR2820430709\%3E3.0.CO;2-Z

Dewys, W. D., Begg, C., Lavin, P. T., Band, P. R., Bennett, J. M., Bertino, J. R., et al. (1980). Prognostic effect of weight loss prior to chemotherapy in cancer patients. Am. J. Med. 69, 491-497. doi: 10.1016/S0149-2918(05)80001-3

Di Sebastiano, K. M., and Mourtzakis, M. (2012). A critical evaluation of body composition modalities used to assess adipose and skeletal muscle tissue in cancer. Appl. Physiol. Nutr. Metab. 37, 811-821. doi: 10.1139/h2012-079

Ebrahimi, B., Tucker, S. L., Li, D., Abbruzzese, J. L., and Kurzrock, R. (2004). Cytokines in pancreatic carcinoma: correlation with phenotypic characteristics and prognosis. Cancer 101, 2727-2736. doi: 10.1002/cncr.20672

Eley, H. L., and Tisdale, M. J. (2007). Skeletal muscle atrophy, a link between depression of protein synthesis and increase in degradation. J. Biol. Chem. 282, 7087-7097. doi: 10.1074/jbc.M610378200

el-Kamar, F. G., Grossbard, M. L., and Kozuch, P. S. (2003). Metastatic pancreatic cancer: emerging strategies in chemotherapy and palliative care. Oncologist 8, 18-34. doi: 10.1634/theoncologist.8-1-18

Faggioni, R., Fuller, J., Moser, A., Feingold, K. R., and Grunfeld, C. (1997). LPS-induced anorexia in leptin-deficient (ob/ob) and leptin receptor-deficient (db/db) mice. Am. J. Physiol. 273, R181-R186.

Fearon, K., Arends, J., and Baracos, V. (2013). Understanding the mechanisms and treatment options in cancer cachexia. Nat. Rev. Clin. Oncol. 10, 90-99. doi: 10.1038/nrclinonc.2012.209

Fearon, K. C. (2008). Cancer cachexia: developing multimodal therapy for a multidimensional problem. Eur. J. Cancer 44, 1124-1132. doi: 10.1016/j.ejca.2008.02.033

Fearon, K. C. (2012). The 2011 ESPEN Arvid Wretlind lecture: cancer cachexia: the potential impact of translational research on patient-focused outcomes. Clin. Nutr. 31, 577-582. doi: 10.1016/j.clnu.2012.06.012

Fearon, K. C., Barber, M. D., Falconer, J. S., McMillan, D. C., Ross, J. A., and Preston, T. (1999). Pancreatic cancer as a model: inflammatory mediators, acute-phase response, and cancer cachexia. World J. Surg. 23, 584-588. doi: 10.1007/PL00012351

Fearon, K. C., Barber, M. D., Moses, A. G., Ahmedzai, S. H., Taylor, G. S., Tisdale, M. J., et al. (2006a). Double-blind, placebo-controlled, randomized study of eicosapentaenoic acid diester in patients with cancer cachexia. J. Clin. Oncol. 24, 3401-3407. doi: 10.1200/JCO.2005.04.5724

Fearon, K., Strasser, F., Anker, S. D., Bosaeus, I., Bruera, E., Fainsinger, R. L., et al. (2011). Definition and classification of cancer cachexia: an 
international consensus. Lancet Oncol. 12, 489-495. doi: 10.1016/S14702045(10)70218-7

Fearon, K. C., Von Meyenfeldt, M. F., Moses, A. G., Van Geenen, R., Roy, A., Gouma, D. J., et al. (2003). Effect of a protein and energy dense N-3 fatty acid enriched oral supplement on loss of weight and lean tissue in cancer cachexia: a randomised double blind trial. Gut 52, 1479-1486. doi: 10.1136/gut.52.10.1479

Fearon, K. C., Voss, A. C., Hustead, D. S., and Group, C. C. (2006b). Definition of cancer cachexia: effect of weight loss, reduced food intake, and systemic inflammation on functional status and prognosis. Am. J. Clin. Nutr. 83, 1345-1350.

Felix, K., Fakelman, F., Hartmann, D., Giese, N. A., Gaida, M. M., Schnölzer, M., et al. (2011). Identification of serum proteins involved in pancreatic cancer cachexia. Life Sci. 88, 218-225. doi: 10.1016/j.lfs.2010.11.011

Finck, B. N., Kelley, K. W., Dantzer, R., and Johnson, R. W. (1998). In vivo and in vitro evidence for the involvement of tumor necrosis factor-alpha in the induction of leptin by lipopolysaccharide. Endocrinology 139, 2278-2283.

Gelin, J., Andersson, C., and Lundholm, K. (1991a). Effects of indomethacin, cytokines, and cyclosporin A on tumor growth and the subsequent development of cancer cachexia. Cancer Res. 51, 880-885.

Gelin, J., Moldawer, L. L., Lönnroth, C., Sherry, B., Chizzonite, R., and Lundholm, K. (1991b). Role of endogenous tumor necrosis factor alpha and interleukin 1 for experimental tumor growth and the development of cancer cachexia. Cancer Res. 51, 415-421.

Gordon, J. N., Trebble, T. M., Ellis, R. D., Duncan, H. D., Johns, T., and Goggin, P. M. (2005). Thalidomide in the treatment of cancer cachexia: a randomised placebo controlled trial. Gut 54, 540-545. doi: 10.1136/gut.2004.047563

Grunfeld, C., Zhao, C., Fuller, J., Pollack, A., Moser, A., Friedman, J., et al. (1996). Endotoxin and cytokines induce expression of leptin, the ob gene product, in hamsters. J. Clin. Invest. 97, 2152-2157. doi: 10.1172/JCI118653

Guttridge, D. C., Mayo, M. W., Madrid, L. V., Wang, C. Y., and Baldwin, A. S. (2000). NF-kappaB-induced loss of MyoD messenger RNA: possible role in muscle decay and cachexia. Science 289, 2363-2366. doi: 10.1126/science.289.5488.2363

Hammarstedt, A., Isakson, P., Gustafson, B., and Smith, U. (2007). Wntsignaling is maintained and adipogenesis inhibited by TNFalpha but not MCP-1 and resistin. Biochem. Biophys. Res. Commun. 357, 700-706. doi: 10.1016/j.bbrc.2007.03.202

He, W. A., Berardi, E., Cardillo, V. M., Acharyya, S., Aulino, P., Thomas-Ahner, J., et al. (2013). NF-кB-mediated Pax7 dysregulation in the muscle microenvironment promotes cancer cachexia. J. Clin. Invest. 123, 4821-4835. doi: 10.1172/JCI68523

Heisler, L. K., Cowley, M. A., Tecott, L. H., Fan, W., Low, M. J., Smart, J. L., et al. (2002). Activation of central melanocortin pathways by fenfluramine. Science 297, 609-611. doi: 10.1126/science.1072327

Hirai, K., Hussey, H. J., Barber, M. D., Price, S. A., and Tisdale, M. J. (1998). Biological evaluation of a lipid-mobilizing factor isolated from the urine of cancer patients. Cancer Res. 58, 2359-2365.

Hussey, H. J., and Tisdale, M. J. (1999). Effect of a cachectic factor on carbohydrate metabolism and attenuation by eicosapentaenoic acid. Br. J. Cancer 80, 1231-1235. doi: 10.1038/sj.bjc.6690490

Imoto, A., Mitsunaga, S., Inagaki, M., Aoyagi, K., Sasaki, H., Ikeda, M., et al. (2012). Neural invasion induces cachexia via astrocytic activation of neural route in pancreatic cancer. Int. J. Cancer 131, 2795-2807. doi: 10.1002/ijc.27594

Inui, A. (1999). Cancer anorexia-cachexia syndrome: are neuropeptides the key? Cancer Res. 59, 4493-4501.

Islam-Ali, B., Khan, S., Price, S. A., and Tisdale, M. J. (2001). Modulation of adipocyte G-protein expression in cancer cachexia by a lipid-mobilizing factor (LMF). Br. J. Cancer 85, 758-763. doi: 10.1054/bjoc.2001.1992

Janik, J. E., Curti, B. D., Considine, R. V., Rager, H. C., Powers, G. C., Alvord, W. G., et al. (1997). Interleukin 1 alpha increases serum leptin concentrations in humans. J. Clin. Endocrinol. Metab. 82, 3084-3086.

Jatoi, A., and Loprinzi, C. L. (2001). Current management of cancer-associated anorexia and weight loss. Oncology (Williston Park) 15, 497-502, 508. discussion: 508-510.

Jatoi, A., Rowland, K., Loprinzi, C. L., Sloan, J. A., Dakhil, S. R., MacDonald, N., et al. (2004). An eicosapentaenoic acid supplement versus megestrol acetate versus both for patients with cancer-associated wasting: a North Central Cancer Treatment Group and National Cancer Institute of Canada collaborative effort. J. Clin. Oncol. 22, 2469-2476. doi: 10.1200/JCO.2004.06.024

Jatoi, A., Windschitl, H. E., Loprinzi, C. L., Sloan, J. A., Dakhil, S. R., Mailliard, J. A., et al. (2002). Dronabinol versus megestrol acetate versus combination therapy for cancer-associated anorexia: a North Central Cancer Treatment Group study. J. Clin. Oncol. 20, 567-573. doi: 10.1200/JCO.20.2.567

Karayiannakis, A. J., Syrigos, K. N., Polychronidis, A., Pitiakoudis, M., Bounovas, A., and Simopoulos, K. (2001). Serum levels of tumor necrosis factor-alpha and nutritional status in pancreatic cancer patients. Anticancer Res. 21, 1355-1358.

Khan, S., and Tisdale, M. J. (1999). Catabolism of adipose tissue by a tumour-produced lipid-mobilising factor. Int. J. Cancer 80, 444-447. doi: $\quad 10.1002 /($ SICI) 1097-0215(19990129)80:3\%3C444::AID-IJC18\%3E3. 3.CO;2-L

Kraft, M., Kraft, K., Gartner, S., Mayerle, J., Simon, P., Weber, E., et al. (2012). L-Carnitine-supplementation in advanced pancreatic cancer (CARPAN)-a randomized multicentre trial. Nutr. J. 11:52. doi: 10.1186/1475-2891-11-52

Lai, V., George, J., Richey, L., Kim, H. J., Cannon, T., Shores, C., et al. (2008). Results of a pilot study of the effects of celecoxib on cancer cachexia in patients with cancer of the head, neck, and gastrointestinal tract. Head Neck 30, 67-74. doi: 10.1002/hed.20662

Laviano, A., Meguid, M. M., and Rossi-Fanelli, F. (2003). Cancer anorexia: clinical implications, pathogenesis, and therapeutic strategies. Lancet Oncol. 4, 686-694. doi: 10.1016/S1470-2045(03)01247-6

Leśniak, W., Bała, M., Jaeschke, R., and Krzakowski, M. (2008). Effects of megestrol acetate in patients with cancer anorexia-cachexia syndrome-a systematic review and meta-analysis. Pol. Arch. Med. Wewn. 118, 636-644.

Li, G., Klein, R. L., Matheny, M., King, M. A., Meyer, E. M., and Scarpace, P. J. (2002). Induction of uncoupling protein 1 by central interleukin-6 gene delivery is dependent on sympathetic innervation of brown adipose tissue and underlies one mechanism of body weight reduction in rats. Neuroscience $115,879-889$. doi: 10.1016/S0306-4522(02)00447-5

Li, Y. P., and Reid, M. B. (2000). NF-kappaB mediates the protein loss induced by TNF-alpha in differentiated skeletal muscle myotubes. Am. J. Physiol. Regul. Integr. Comp. Physiol. 279, R1165-R1170.

Llovera, M., Carbó, N., López-Soriano, J., García-Martínez, C., Busquets, S., Alvarez, B., et al. (1998). Different cytokines modulate ubiquitin gene expression in rat skeletal muscle. Cancer Lett. 133, 83-87. doi: 10.1016/S03043835(98)00216-X

Loprinzi, C. L., Ellison, N. M., Schaid, D. J., Krook, J. E., Athmann, L. M., Dose, A. M., et al. (1990). Controlled trial of megestrol acetate for the treatment of cancer anorexia and cachexia. J. Natl. Cancer Inst. 82, 1127-1132. doi: 10.1093/jnci/82.13.1127

Loprinzi, C. L., Kugler, J. W., Sloan, J. A., Mailliard, J. A., Krook, J. E., Wilwerding, M. B., et al. (1999). Randomized comparison of megestrol acetate versus dexamethasone versus fluoxymesterone for the treatment of cancer anorexia/cachexia. J. Clin. Oncol. 17, 3299-3306.

Loprinzi, C. L., Michalak, J. C., Schaid, D. J., Mailliard, J. A., Athmann, L. M., Goldberg, R. M., et al. (1993a). Phase III evaluation of four doses of megestrol acetate as therapy for patients with cancer anorexia and/or cachexia. J. Clin. Oncol. 11, 762-767.

Loprinzi, C. L., Schaid, D. J., Dose, A. M., Burnham, N. L., and Jensen, M. D. (1993b). Body-composition changes in patients who gain weight while receiving megestrol acetate. J. Clin. Oncol. 11, 152-154.

Lorite, M. J., Cariuk, P., and Tisdale, M. J. (1997). Induction of muscle protein degradation by a tumour factor. Br. J. Cancer 76, 1035-1040. doi: 10.1038/bjc. 1997.504

Lorite, M. J., Smith, H. J., Arnold, J. A., Morris, A., Thompson, M. G., and Tisdale, M. J. (2001). Activation of ATP-ubiquitin-dependent proteolysis in skeletal muscle in vivo and murine myoblasts in vitro by a proteolysis-inducing factor (PIF). Br. J. Cancer 85, 297-302. doi: 10.1054/bjoc.2001.1879

Lundholm, K., Gelin, J., Hyltander, A., Lönnroth, C., Sandström, R., Svaninger, G., et al. (1994). Anti-inflammatory treatment may prolong survival in undernourished patients with metastatic solid tumors. Cancer Res. 54, 5602-5606.

Maltoni, M., Fabbri, L., Nanni, O., Scarpi, E., Pezzi, L., Flamini, E., et al. (1997). Serum levels of tumour necrosis factor alpha and other cytokines do not correlate with weight loss and anorexia in cancer patients. Support Care Cancer 5, 130-135. doi: 10.1007/BF01262570

Mantovani, G., Macciò, A., Lai, P., Massa, E., Ghiani, M., and Santona, M. C. (1998a). Cytokine activity in cancer-related anorexia/cachexia: role of megestrol acetate and medroxyprogesterone acetate. Semin Oncol. 25(2 Suppl. 6), 45-52.

Mantovani, G., Macciò, A., Lai, P., Massa, E., Ghiani, M., and Santona, M. C. (1998b). Cytokine involvement in cancer anorexia/cachexia: role of megestrol acetate and medroxyprogesterone acetate on cytokine downregulation 
and improvement of clinical symptoms. Crit. Rev. Oncog. 9, 99-106. doi: 10.1615/CritRevOncog.v9.i2.10

Mantovani, G., Macciò, A., Madeddu, C., Serpe, R., Massa, E., Dessì, M., et al. (2010). Randomized phase III clinical trial of five different arms of treatment in 332 patients with cancer cachexia. Oncologist 15, 200-211. doi: 10.1634/theoncologist.2009-0153

Mantovani, G., Macciò, A., Mura, L., Massa, E., Mudu, M. C., Mulas, C., et al. (2000). Serum levels of leptin and proinflammatory cytokines in patients with advanced-stage cancer at different sites. J. Mol. Med. (Berl.) 78, 554-561. doi: 10.1007/s001090000137

Marks, D., and Cone, R. D. (2003). The role of the melanocortin-3 receptor in cachexia. Ann. N.Y. Acad. Sci. 994, 258-266. doi: 10.1111/j.17496632.2003.tb03188.x

Marks, D. L., Butler, A. A., Turner, R., Brookhart, G., and Cone, R. D. (2003). Differential role of melanocortin receptor subtypes in cachexia. Endocrinology 144, 1513-1523. doi: 10.1210/en.2002-221099

Martignoni, M. E., Dimitriu, C., Bachmann, J., Krakowski-Rosen, H., Ketterer, K., Kinscherf, R., et al. (2009). Liver macrophages contribute to pancreatic cancerrelated cachexia. Oncol. Rep. 21, 363-369. doi: 10.3892/or_00000231

Martignoni, M. E., Kunze, P., Hildebrandt, W., Künzli, B., Berberat, P., Giese, T., et al. (2005). Role of mononuclear cells and inflammatory cytokines in pancreatic cancer-related cachexia. Clin. Cancer Res. 11, 5802-5808. doi: 10.1158/1078-0432.CCR-05-0185

McCarthy, H. D., Crowder, R. E., Dryden, S., and Williams, G. (1994). Megestrol acetate stimulates food and water intake in the rat: effects on regional hypothalamic neuropeptide Y concentrations. Eur. J. Pharmacol. 265, 99-102. doi: 10.1016/0014-2999(94)90229-1

McMillan, D. C., Leen, E., Smith, J., Sturgeon, C., Preston, T., Cooke, T. G., et al. (1995). Effect of extended ibuprofen administration on the acute phase protein response in colorectal cancer patients. Eur. J. Surg. Oncol. 21, 531-534. doi: 10.1016/S0748-7983(95)97157-2

McMillan, D. C., O'Gorman, P., Fearon, K. C., and McArdle, C. S. (1997). A pilot study of megestrol acetate and ibuprofen in the treatment of cachexia in gastrointestinal cancer patients. Br. J. Cancer 76, 788-790. doi: 10.1038/bjc.1997.463

McMillan, D. C., Wigmore, S. J., Fearon, K. C., O'Gorman, P., Wright, C. E., and McArdle, C. S. (1999). A prospective randomized study of megestrol acetate and ibuprofen in gastrointestinal cancer patients with weight loss. Br. J. Cancer 79, 495-500. doi: 10.1038/sj.bjc.6690077

Meydani, S. N., Lichtenstein, A. H., Cornwall, S., Meydani, M., Goldin, B. R., Rasmussen, H., et al. (1993). Immunologic effects of national cholesterol education panel step-2 diets with and without fish-derived N-3 fatty acid enrichment. J. Clin. Invest. 92, 105-113. doi: 10.1172/JCI116537

Mitsunaga, S., Kinoshita, T., Hasebe, T., Nakagohri, T., Konishi, M., Takahashi, S., et al. (2008). Low serum level of cholinesterase at recurrence of pancreatic cancer is a poor prognostic factor and relates to systemic disorder and nerve plexus invasion. Pancreas 36, 241-248. doi: 10.1097/MPA.0b013e3181 $5 \mathrm{~b} 6 \mathrm{~b} 2 \mathrm{~b}$

Moses, A. G., Maingay, J., Sangster, K., Fearon, K. C., and Ross, J. A. (2009). Pro-inflammatory cytokine release by peripheral blood mononuclear cells from patients with advanced pancreatic cancer: relationship to acute phase response and survival. Oncol. Rep. 21, 1091-1095. doi: 10.3892/or_00000328

Moses, A. W., Slater, C., Preston, T., Barber, M. D., and Fearon, K. C. (2004). Reduced total energy expenditure and physical activity in cachectic patients with pancreatic cancer can be modulated by an energy and protein dense oral supplement enriched with n-3 fatty acids. Br. J. Cancer 90, 996-1002. doi: 10.1038/sj.bjc.6601620

Nelson, K., Walsh, D., Deeter, P., and Sheehan, F. (1994). A phase II study of delta9-tetrahydrocannabinol for appetite stimulation in cancer-associated anorexia. J. Palliat. Care 10, 14-18.

Nitenberg, G., and Raynard, B. (2000). Nutritional support of the cancer patient: issues and dilemmas. Crit. Rev. Oncol. Hematol. 34, 137-168. doi: 10.1016/S1040-8428(00)00048-2

Nixon, D. W., Lawson, D. H., Kutner, M., Ansley, J., Schwarz, M., Heymsfield, S., et al. (1981). Hyperalimentation of the cancer patient with protein-calorie undernutrition. Cancer Res. 41, 2038-2045.

Olguin, H. C., and Olwin, B. B. (2004). Pax-7 up-regulation inhibits myogenesis and cell cycle progression in satellite cells: a potential mechanism for self-renewal. Dev. Biol. 275, 375-388. doi: 10.1016/j.ydbio.2004.08.015
Ottery, F. (1996). Supportive nutritional management of the patient with pancreatic cancer. Oncology (Williston Park) 10, 26-32.

Ovesen, L., Allingstrup, L., Hannibal, J., Mortensen, E. L., and Hansen, O. P. (1993). Effect of dietary counseling on food intake, body weight, response rate, survival, and quality of life in cancer patients undergoing chemotherapy: a prospective, randomized study. J. Clin. Oncol. 11, 2043-2049.

Pascual López, A., Roqué i Figuls, M., Urrútia Cuchi, G., Berenstein, E. G., Almenar Pasies, B., Balcells Alegre, M., et al. (2004). Systematic review of megestrol acetate in the treatment of anorexia-cachexia syndrome. J. Pain Symptom Manage. 27, 360-369. doi: 10.1016/j.jpainsymman.2003.09.007

Pausch, T., Hartwig, W., Hinz, U., Swolana, T., Bundy, B. D., Hackert, T., et al. (2012). Cachexia but not obesity worsens the postoperative outcome after pancreatoduodenectomy in pancreatic cancer. Surgery 152, S81-S88. doi: 10.1016/j.surg.2012.05.028

Pelzer, U., Arnold, D., Gövercin, M., Stieler, J., Doerken, B., Riess, H., et al. (2010). Parenteral nutrition support for patients with pancreatic cancer. Results of a phase II study. BMC Cancer 10:86. doi: 10.1186/1471-2407-10-86

Plata-Salamán, C. R. (1991). Dexamethasone inhibits food intake suppression induced by low doses of interleukin-1 beta administered intracerebroventricularly. Brain Res. Bull. 27, 737-738. doi: 10.1016/0361-9230(91)90055-O

Prado, C. M., Birdsell, L. A., and Baracos, V. E. (2009). The emerging role of computerized tomography in assessing cancer cachexia. Curr. Opin. Support. Palliat. Care 3, 269-275. doi: 10.1097/SPC.0b013e328331124a

Preston, T., Fearon, K. C., McMillan, D. C., Winstanley, F. P., Slater, C., Shenkin, A., et al. (1995). Effect of ibuprofen on the acute-phase response and protein metabolism in patients with cancer and weight loss. Br. J. Surg. 82, 229-234. doi: 10.1002/bjs. 1800820233

Preston, T., Slater, C., McMillan, D. C., Falconer, J. S., Shenkin, A., and Fearon, K. C. (1998). Fibrinogen synthesis is elevated in fasting cancer patients with an acute phase response. J. Nutr. 128, 1355-1360.

Rigas, J. R., Schuster, M., Orlov, S. V., Milovanovic, B., Prabhash, K., Smith, J. T., et al. (2010). Effect of ALD518, a humanized anti-IL-6 antibody, on lean body mass loss and symptoms in patients with advanced non-small cell lung cancer (NSCLC): results of a phase II randomized, double-blind safety and efficacy trial. J. Clin. Oncol. 28:abstract 7622.

Russell, S. T., Eley, H., and Tisdale, M. J. (2007). Role of reactive oxygen species in protein degradation in murine myotubes induced by proteolysis-inducing factor and angiotensin II. Cell Signal. 19, 1797-1806. doi: 10.1016/j.cellsig.2007.04.003

Russell, S. T., Hirai, K., and Tisdale, M. J. (2002). Role of beta3-adrenergic receptors in the action of a tumour lipid mobilizing factor. Br. J. Cancer 86, 424-428. doi: 10.1038/sj.bjc.6600086

Russell, S. T., and Tisdale, M. J. (2002). Effect of a tumour-derived lipid-mobilising factor on glucose and lipid metabolism in vivo. Br. J. Cancer 87, 580-584. doi: 10.1038/sj.bjc.6600493

Rydén, M., Agustsson, T., Laurencikiene, J., Britton, T., Sjölin, E., Isaksson, B., et al. (2008). Lipolysis-not inflammation, cell death, or lipogenesis-is involved in adipose tissue loss in cancer cachexia. Cancer 113, 1695-1704. doi: $10.1002 /$ cncr.23802

Rydén, M., Arvidsson, E., Blomqvist, L., Perbeck, L., Dicker, A., and Arner, P. (2004). Targets for TNF-alpha-induced lipolysis in human adipocytes. Biochem. Biophys. Res. Commun. 318, 168-175. doi: 10.1016/j.bbrc.2004.04.010

Sampaio, E. P., Sarno, E. N., Galilly, R., Cohn, Z. A., and Kaplan, G. (1991). Thalidomide selectively inhibits tumor necrosis factor alpha production by stimulated human monocytes. J. Exp. Med. 173, 699-703. doi: 10.1084/jem.173.3.699

Sarraf, P., Frederich, R. C., Turner, E. M., Ma, G., Jaskowiak, N. T., Rivet, D. J., et al. (1997). Multiple cytokines and acute inflammation raise mouse leptin levels: potential role in inflammatory anorexia. J. Exp. Med. 185, 171-175. doi: 10.1084/jem.185.1.171

Scarlett, J. M., Jobst, E. E., Enriori, P. J., Bowe, D. D., Batra, A. K., Grant, W. F., et al. (2007). Regulation of central melanocortin signaling by interleukin-1 beta. Endocrinology 148, 4217-4225. doi: 10.1210/en.2007-0017

Schittek, B., Hipfel, R., Sauer, B., Bauer, J., Kalbacher, H., Stevanovic, S., et al. (2001). Dermcidin: a novel human antibiotic peptide secreted by sweat glands. Nat. Immunol. 2, 1133-1137. doi: 10.1038/ni732

Schuster, M., Rigas, J. R., Orlov, S. V., Milovanovic, B., Prabhash, K., Smith, J. T., et al. (2010). ALD518, a humanized anti-IL-6 antibody, treats anemia in patients with advanced non-small cell lung cancer (NSCLC): results of a phase II, 
randomized, double-blind, placebo-controlled trial. J. Clin. Oncol. 28:abstract 7631.

Shintani, F., Kanba, S., Nakaki, T., Nibuya, M., Kinoshita, N., Suzuki, E., et al. (1993). Interleukin-1 beta augments release of norepinephrine, dopamine, and serotonin in the rat anterior hypothalamus. J. Neurosci. 13, 3574-3581.

Simons, J. P., Schols, A. M., Campfield, L. A., Wouters, E. F., and Saris, W. H. (1997). Plasma concentration of total leptin and human lung-cancer-associated cachexia. Clin. Sci. (Lond.) 93, 273-277.

Simons, J. P., Schols, A. M., Westerterp, K. R., ten Velde, G. P., and Wouters, E. F. (1995). The use of bioelectrical impedance analysis to predict total body water in patients with cancer cachexia. Am. J. Clin. Nutr. 61, 741-745.

Smith, H. J., and Tisdale, M. J. (2003). Signal transduction pathways involved in proteolysis-inducing factor induced proteasome expression in murine myotubes. Br. J. Cancer 89, 1783-1788. doi: 10.1038/sj.bjc.6601328

Smith, H. J., Wyke, S. M., and Tisdale, M. J. (2004). Role of protein kinase C and NF-kappaB in proteolysis-inducing factor-induced proteasome expression in C(2)C(12) myotubes. Br. J. Cancer 90, 1850-1857. doi: 10.1038/sj.bjc.6601767

Strassmann, G., Fong, M., Kenney, J. S., and Jacob, C. O. (1992). Evidence for the involvement of interleukin 6 in experimental cancer cachexia. J. Clin. Invest. 89, 1681-1684. doi: 10.1172/JCI115767

Suzuki, H., Asakawa, A., Amitani, H., Fujitsuka, N., Nakamura, N., and Inui, A. (2013). Cancer cachexia pathophysiology and translational aspect of herbal medicine. Jpn. J. Clin. Oncol. 43, 695-705. doi: 10.1093/jjco/hyt075

Tan, B. H., Birdsell, L. A., Martin, L., Baracos, V. E., and Fearon, K. C. (2009). Sarcopenia in an overweight or obese patient is an adverse prognostic factor in pancreatic cancer. Clin. Cancer Res. 15, 6973-6979. doi: 10.1158/10780432.CCR-09-1525

Tisdale, M. J. (1996). Inhibition of lipolysis and muscle protein degradation by EPA in cancer cachexia. Nutrition 12, S31-S33. doi: 10.1016/0899-9007(95)00066-6

Tisdale, M. J., and Beck, S. A. (1991). Inhibition of tumour-induced lipolysis in vitro and cachexia and tumour growth in vivo by eicosapentaenoic acid. Biochem. Pharmacol. 41, 103-107. doi: 10.1016/0006-2952(91)90016-X

Todorov, P., Cariuk, P., McDevitt, T., Coles, B., Fearon, K., and Tisdale, M. (1996). Characterization of a cancer cachectic factor. Nature 379, 739-742. doi: 10.1038/379739a0

Todorov, P. T., Deacon, M., and Tisdale, M. J. (1997). Structural analysis of a tumor-produced sulfated glycoprotein capable of initiating muscle protein degradation. J. Biol. Chem. 272, 12279-12288. doi: 10.1074/jbc.272.19.12279

Todorov, P. T., McDevitt, T. M., Meyer, D. J., Ueyama, H., Ohkubo, I., and Tisdale, M. J. (1998). Purification and characterization of a tumor lipid-mobilizing factor. Cancer Res. 58, 2353-2358.

Tsoli, M., Moore, M., Burg, D., Painter, A., Taylor, R., Lockie, S. H., et al. (2012). Activation of thermogenesis in brown adipose tissue and dysregulated lipid metabolism associated with cancer cachexia in mice. Cancer Res. 72, 4372-4382. doi: 10.1158/0008-5472.CAN-11-3536

Tuca, A., Jimenez-Fonseca, P., and Gascón, P. (2013). Clinical evaluation and optimal management of cancer cachexia. Crit. Rev. Oncol. Hematol. 88, 625-636. doi: 10.1016/j.critrevonc.2013.07.015

Wallace, A. M., Sattar, N., and McMillan, D. C. (1998). Effect of weight loss and the inflammatory response on leptin concentrations in gastrointestinal cancer patients. Clin. Cancer Res. 4, 2977-2979.

Watchorn, T. M., Dowidar, N., Dejong, C. H., Waddell, I. D., Garden, O. J., and Ross, J. A. (2005). The cachectic mediator proteolysis inducing factor activates NF-kappaB and STAT3 in human Kupffer cells and monocytes. Int. J. Oncol. 27, 1105-1111.

Watchorn, T. M., Waddell, I., Dowidar, N., and Ross, J. A. (2001). Proteolysisinducing factor regulates hepatic gene expression via the transcription factors NF-(kappa)B and STAT3. FASEB J. 15, 562-564.

Westman, G., Bergman, B., Albertsson, M., Kadar, L., Gustavsson, G., Thaning, L., et al. (1999). Megestrol acetate in advanced, progressive, hormone-insensitive cancer. Effects on the quality of life: a placebo-controlled, randomised, multicentre trial. Eur. J. Cancer 35, 586-595. doi: 10.1016/S0959-8049(98)00398-0

Whitehouse, A. S., Khal, J., and Tisdale, M. J. (2003). Induction of protein catabolism in myotubes by $15(\mathrm{~S})$-hydroxyeicosatetraenoic acid through increased expression of the ubiquitin-proteasome pathway. Br. J. Cancer 89, 737-745. doi: 10.1038/sj.bjc.6601184

Whitehouse, A. S., and Tisdale, M. J. (2003). Increased expression of the ubiquitinproteasome pathway in murine myotubes by proteolysis-inducing factor (PIF) is associated with activation of the transcription factor NF-kappaB. Br. J. Cancer 89, 1116-1122. doi: 10.1038/sj.bjc.6601132
Wigmore, S. J., Barber, M. D., Ross, J. A., Tisdale, M. J., and Fearon, K. C. (2000b). Effect of oral eicosapentaenoic acid on weight loss in patients with pancreatic cancer. Nutr. Cancer 36, 177-184. doi: 10.1207/S1532791 4NC3602_6

Wigmore, S. J., Falconer, J. S., Plester, C. E., Ross, J. A., Maingay, J. P., Carter, D. C., et al. (1995). Ibuprofen reduces energy expenditure and acute-phase protein production compared with placebo in pancreatic cancer patients. Br. J. Cancer 72, 185-188. doi: 10.1038/bjc. 1995.300

Wigmore, S. J., Fearon, K. C., Maingay, J. P., and Ross, J. A. (1997a). Downregulation of the acute-phase response in patients with pancreatic cancer cachexia receiving oral eicosapentaenoic acid is mediated via suppression of interleukin-6. Clin. Sci. (Lond.) 92, 215-221.

Wigmore, S. J., Plester, C. E., Ross, J. A., and Fearon, K. C. (1997b). Contribution of anorexia and hypermetabolism to weight loss in anicteric patients with pancreatic cancer. Br. J. Surg. 84, 196-197. doi: 10.1002/bjs.18008 40214

Wigmore, S. J., Ross, J. A., Falconer, J. S., Plester, C. E., Tisdale, M. J., Carter, D. C., et al. (1996). The effect of polyunsaturated fatty acids on the progress of cachexia in patients with pancreatic cancer. Nutrition 12, S27-S30. doi: 10.1016/0899-9007(95)00078-X

Wigmore, S. J., Todorov, P. T., Barber, M. D., Ross, J. A., Tisdale, M. J., and Fearon, K. C. (2000b). Characteristics of patients with pancreatic cancer expressing a novel cancer cachectic factor. Br. J. Surg. 87, 53-58. doi: 10.1046/j.13652168.2000.01317.x

Willox, J. C., Corr, J., Shaw, J., Richardson, M., Calman, K. C., and Drennan, M. (1984). Prednisolone as an appetite stimulant in patients with cancer. Br. Med. J. (Clin. Res. Ed.). 288, 27. doi: 10.1136/bmj.288.6410.27

Wisse, B. E., Frayo, R. S., Schwartz, M. W., and Cummings, D. E. (2001). Reversal of cancer anorexia by blockade of central melanocortin receptors in rats. Endocrinology 142, 3292-3301. doi: 10.1210/endo.142.8.8324

Wyke, S. M., Khal, J., and Tisdale, M. J. (2005). Signalling pathways in the induction of proteasome expression by proteolysis-inducing factor in murine myotubes. Cell Signal. 17, 67-75. doi: 10.1016/j.cellsig. 2004.05.015

Wyke, S. M., and Tisdale, M. J. (2005). NF-kappaB mediates proteolysis-inducing factor induced protein degradation and expression of the ubiquitin-proteasome system in skeletal muscle. Br. J. Cancer 92, 711-721. doi: 10.1038/sj.bjc.66 02402

Zamanian-Daryoush, M., Mogensen, T. H., DiDonato, J. A., and Williams, B. R. (2000). NF-kappaB activation by double-stranded-RNA-activated protein kinase (PKR) is mediated through NF-kappaB-inducing kinase and IkappaB kinase. Mol. Cell Biol. 20, 1278-1290. doi: 10.1128/MCB.20.4.1278-1290. 2000

Zhang, H. H., Halbleib, M., Ahmad, F., Manganiello, V. C., and Greenberg, A. S. (2002). Tumor necrosis factor-alpha stimulates lipolysis in differentiated human adipocytes through activation of extracellular signal-related kinase and elevation of intracellular cAMP. Diabetes 51, 2929-2935. doi: 10.2337/diabetes.51.10.2929

Zhou, X., Wang, J. L., Lu, J., Song, Y., Kwak, K. S., Jiao, Q., et al. (2010). Reversal of cancer cachexia and muscle wasting by ActRIIB antagonism leads to prolonged survival. Cell 142, 531-543. doi: 10.1016/j.cell.2010.07.011

Conflict of Interest Statement: The authors declare that the research was conducted in the absence of any commercial or financial relationships that could be construed as a potential conflict of interest.

Received: 18 December 2013; accepted: 13 February 2014; published online: 03 March 2014.

Citation: Tan CR, Yaffee PM, Jamil LH, Lo SK, Nissen N, Pandol SJ, Tuli R and Hendifar AE (2014) Pancreatic cancer cachexia: a review of mechanisms and therapeutics. Front. Physiol. 5:88. doi: 10.3389/fphys.2014.00088

This article was submitted to Gastrointestinal Sciences, a section of the journal Frontiers in Physiology.

Copyright (C) 2014 Tan, Yaffee, Jamil, Lo, Nissen, Pandol, Tuli and Hendifar. This is an open-access article distributed under the terms of the Creative Commons Attribution License (CC BY). The use, distribution or reproduction in other forums is permitted, provided the original author(s) or licensor are credited and that the original publication in this journal is cited, in accordance with accepted academic practice. No use, distribution or reproduction is permitted which does not comply with these terms. 